\title{
Transition-Metal-Free and Visible-Light-Mediated Desulfonylation and Dehalogenation Reactions: Hantzsch Ester Anion as Electron and Hydrogen Atom Donor
}

\author{
Micaela D. Heredia, Walter D. Guerra, Silvia M. Barolo, Santiago J. Fornasier, Roberto A. Rossi, \\ and María E. Budén*
}

Cite This: https://dx.doi.org/10.1021/acs.joc.0c01523

Read Online

ABSTRACT: Novel approaches for $\mathrm{N}$ - and O-desulfonylation under room temperature (rt) and transition-metal-free conditions have been developed. The first methodology involves the transformation of a variety of $\mathrm{N}$-sulfonyl heterocycles and phenyl benzenesulfonates to the corresponding desulfonylated products in good to excellent yields using only $\mathrm{KO}^{t} \mathrm{Bu}$ in dimethyl sulfoxide (DMSO) at rt. Alternately, a visible light method has been used for deprotection of $N$-methyl- $N$-arylsulfonamides with Hantzsch ester (HE) anion serving as the visible-light-absorbing reagent and electron and hydrogen

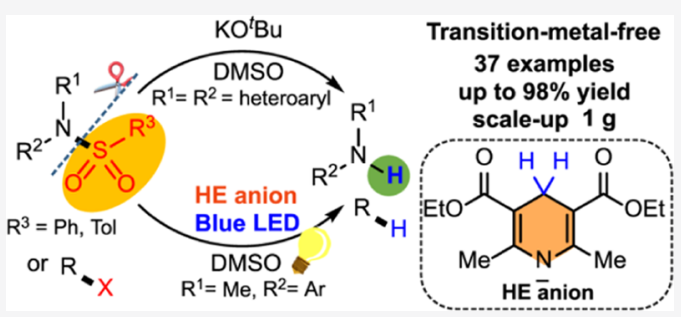
atom donor to promote the desulfonylation reaction. The $\mathrm{HE}$ anion can be easily prepared in situ by reaction of the corresponding $\mathrm{HE}$ with $\mathrm{KO}^{t} \mathrm{Bu}$ in $\mathrm{DMSO}$ at $\mathrm{rt}$. Both protocols were further explored in terms of synthetic scope as well as mechanistic aspects to rationalize key features of desulfonylation processes. Furthermore, the HE anion induces reductive dehalogenation reaction of aryl halides under visible light irradiation.

\section{INTRODUCTION}

Many protecting groups were developed for amine functionality and provide desired stability toward acid, basic, reducing, or oxidizing conditions. ${ }^{1,2}$ In particular, sulfonamides as nitrogen-protecting groups play an important role in amine chemistry. ${ }^{3}$ For instance, benzenesulfonyl or $p$-toluenesulfonyl (tosyl, Ts) groups are easy to introduce, offering extreme robustness and high crystallinity and helping in compound purification. ${ }^{1}$ However, drastic conditions are required to remove sulfonyl groups and, consequently, several methodologies to promote desulfonylation reactions have been described. Deprotection methods can be classified into three large families: acidic reductive conditions, reductions in strongly basic media, or electron transfer (ET) cleavage.

The cleavage of $\mathrm{N}-\mathrm{S}$ bond can be acid-mediated by $\mathrm{HBr}^{4-6} \mathrm{HCl}^{7}{ }^{7} \mathrm{H}_{2} \mathrm{SO}_{4},{ }^{7,8} \quad \mathrm{CF}_{3} \mathrm{COOH}^{9}{ }^{9} \mathrm{CF}_{3} \mathrm{SO}_{3} \mathrm{H}^{10}{ }^{10} \mathrm{HF}-$ pyridine with anisole, ${ }^{11}$ or $\mathrm{CH}_{3} \mathrm{COOH} / \mathrm{HClO}_{4}{ }^{12}$ mostly under very harsh conditions or at high temperatures. Moreover, the $\mathrm{N}$-deprotection method using $\mathrm{HBr}$ requires a bromine scavenger such as phenol ${ }^{4}$ to avoid monobromination and/or dibromination of the aromatic ring of aniline.

Likewise, many methods using strong bases or nucleophiles are well known, such as $\mathrm{NaOH}$ or $\mathrm{KOH}$ in $\mathrm{MeOH},{ }^{13,14} \mathrm{KOH}$ in tetrahydrofuran (THF) $/ \mathrm{H}_{2} \mathrm{O}$ mixture, ${ }^{15} \mathrm{NaO}{ }^{t} \mathrm{Bu}$ in dioxane, ${ }^{16}$ thioglycolate in dimethylformamide (DMF), ${ }^{17}$ $\mathrm{Cs}_{2} \mathrm{CO}_{3}$ in $\mathrm{THF} / \mathrm{MeOH},{ }^{18} \mathrm{PhMe}_{2} \mathrm{SiLi}$ in $\mathrm{THF},{ }^{19}$ sodium bis(2-methoxyethoxy)aluminum hydride in benzene or toluene as solvents ${ }^{20}$ and $n-\mathrm{Bu}_{4} \mathrm{NF}^{21}$ in dry THF. Despite the large number of $\mathrm{N}$-desulfonylation methodologies in basic media, only a few are useful in industries because long-time reactions and high temperatures are required to obtain the corresponding desulfonylated products. In some cases, a phase-transfer catalyst such as cetyltrimethylammonium bromide is needed due to the low solubility of the amines in the media. The use of $\mathrm{MeOH}$ is discouraged by its toxicity and production of toxic methyl $p$-toluenesulfonate as a byproduct, as a consequence of esterification of $p$-toluenesulfonic acid liberated during the reaction. Moreover, $\mathrm{Cs}_{2} \mathrm{CO}_{3}$ in $\mathrm{MeOH}$ produces an $\mathrm{N}$-methylated impurity that is difficult to remove during purification processes ${ }^{18}$ and also $\mathrm{NaOH}$ at reflux in EtOH led to degradation products. ${ }^{22}$

Desulfonylation induced by ET is also widely described. The most common approaches of this type of reductions are promoted by $\mathrm{SmI}_{2},{ }^{23-28} \mathrm{Mg} / \mathrm{MeOH},{ }^{29-33}$ alkali metals, ${ }^{34-39}$ low-valent titanium, ${ }^{40,41}$ organic electron donors, ${ }^{42-44}$ and electrochemistry. ${ }^{45-48}$ In particular, photoinduced ET (PET) has also been applied for desulfonylation reactions. ${ }^{49}$ The PET process under UV irradiation using 2-phenyl- $N, N^{\prime}$ dimethylbenzimidazoline as electron and hydrogen donor has been used in tosyl amide deprotection. ${ }^{50} \mathrm{~N}$-sulfonyl indoles

Received: June 27, 2020

Published: September 7, 2020 
can be deprotected by a PET reaction with $\mathrm{NEt}_{3}$ serving as both an electron and proton donor and $n-\mathrm{Bu}_{3} \mathrm{SnH}$ serving as a hydrogen atom donor. ${ }^{51}$ In 2013, Xiao et al. reported Ndetosylation of tosyl amides using visible light and iridium as photocatalysts with Hantzsch ester (HE, diethyl 2,6-dimethyl1,4-dihydropyridine-3,5-dicarboxylate) as electron donor. ${ }^{52}$ Moreover, in 2018, Hasegawa and co-workers demonstrated that benzimidazolium naphthoxide betaine and 1,3-dimethyl2-hydroxynaphthylbenzimidazoline (HONap-BIH) can serve as light-absorbing, electron and hydrogen atom donor for desulfonylation of $N$-sulfonyl-amides and amines. ${ }^{53,54}$ Another study of Hasegawa has reported a new visible-light-promoted system for desulfonylation process consisting of benzimidazolium aryloxide betaines $\left(\mathrm{BI}^{+}-\mathrm{ArO}^{-}\right)$and stoichiometric hydride-reducing reagents. ${ }^{55}$ More recently, a visible light protocol using $\mathrm{Cu}$ complex/HE has just been developed to deprotect N-heterocycles. ${ }^{56}$ Finally, an acridine radical as a single-electron reductant has been also used for desulfonylation reactions. ${ }^{57}$ However, all of these recent visible light protocols use expensive photocatalysts or even catalysts that are not commercially available.

Over the past few years, Hantzsch esters (HEs) were extensively used in hydrogen transfer reactions. ${ }^{58}$ Additionally, with the continuous advances in the visible light photocatalysis field, ${ }^{59-61}$ HEs have also been used as an electron donor and a proton source in a large number of photoredox processes. $^{62}$ In this sense, a wide range of organic transformations involve the use of transition-metal photocatalysts in combination with $\mathrm{HEs}$ as reductants. ${ }^{63-68}$ Other recent reports demonstrated the formation of an electron donoracceptor (EDA) complex between $\mathrm{HE}$ and $N$-alkoxyl derivatives, $N$-acyloxyphthalimides, $N$-alkyl-pyridinium salts, or heteroaryl $\mathrm{N}$-oxides to undergo PET in the absence of a photocatalyst under visible light irradiation. ${ }^{69-72}$ Furthermore, $\mathrm{HE}$ in the presence of a base was recently used as a visiblelight catalyst to obtain alkenes and diaryl sulfinates. ${ }^{73,74}$

In this context, the development of a convenient, practical, and more economical method to cleavage $\mathrm{N}-\mathrm{S}$ bonds avoiding the use of high temperatures, harmful solvents, and expensive transition-metal catalysts is highly desired. Herein, we describe two efficient transition-metal-free protocols whose application is related to the nature of the sulfonamide moiety. $\mathrm{KO}^{t} \mathrm{Bu}$ in dimethyl sulfoxide (DMSO) at room temperature (rt) provides a clean approach for deprotection of $\mathrm{N}$-sulfonyl heterocycles and phenyl benzenesulfonates. ${ }^{53}$ However, for $N$ methyl- $N$-arylsulfonamides, a stronger reductive method for an effective desulfonylation is needed. Thus, the use of the anion of $\mathrm{HE}$ to promote the deprotection of $\mathrm{N}$-methyl- $\mathrm{N}$ arylsulfonamides under visible light irradiation was explored. In this work, the $\mathrm{HE}$ anion is easily prepared in situ by reaction of the commercial $\mathrm{HE}$ with $\mathrm{KO}^{t} \mathrm{Bu}$ in DMSO. Additionally, $\mathrm{HE}$ anion absorbs light in the visible region; hence, this protocol does not require a transition-metal photocatalyst or an absorbing light complex.

Finally, mechanistic insights were explored to understand the difference in reactivity and the mechanisms involved. The scope of these two methods of $\mathrm{N}-\mathrm{S}$ (or $\mathrm{O}-\mathrm{S}$ ) cleavage was successfully examined using a large variety of $\mathrm{N}$-sulfonyl heterocycles, $\mathrm{N}$-sulfonylamines, and even phenyl benzenesulfonates. Furthermore, the use of $\mathrm{HE}$ anion as visible-lightabsorbing reagent was studied in the reduction of several aryl and heteroaryl halides (RX) including iodide, bromide, and chloride derivatives.

\section{RESULTS}

$N$-Tosylated indole 1a was selected as a model substrate to optimize our $\mathrm{N}$-desulfonylation reaction conditions. As summarized in Table 1, 2a was obtained in $49 \%$ yield when

Table 1. N-Desulfonylation Reaction of $\mathrm{N}$-Indole $1 \mathrm{a}^{a}$

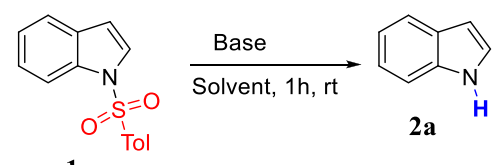

1a

\begin{tabular}{cll} 
entry & \multicolumn{1}{c}{ conditions $^{a}$} & yields $2 \mathrm{a}^{b}$ \\
1 & 3 equiv $\mathrm{KO}^{t} \mathrm{Bu}, \mathrm{DMF}$ & 49 \\
2 & 3 equiv $\mathrm{KO}^{t} \mathrm{Bu}, \mathrm{DMSO}$ & $96(91)^{c}$ \\
3 & 3 equiv $\mathrm{KO}^{t} \mathrm{Bu}, \mathrm{THF}$ & 26 \\
4 & 3 equiv $\mathrm{KO}^{t} \mathrm{Bu}, \mathrm{EtOH}$ & $<5$ \\
5 & 1.1 equiv $\mathrm{KO}^{t} \mathrm{Bu}, \mathrm{DMSO}$ & 48 \\
6 & 3 equiv $\mathrm{K}_{2} \mathrm{CO}_{3}, \mathrm{DMSO}$ & - \\
7 & 3 equiv $\mathrm{Cs}_{2} \mathrm{CO}_{3}, \mathrm{DMSO}$ & - \\
8 & 3 equiv $\mathrm{KOH}, \mathrm{DMSO}^{\circ}$ & - \\
9 & 3 equiv $\mathrm{KOH}, 65{ }^{\circ} \mathrm{C}, \mathrm{DMSO}$ & 12 \\
10 & 3 equiv $\mathrm{NaH}, \mathrm{DMSO}$ & 21 \\
11 & 3 equiv $\mathrm{NaO}{ }^{t} \mathrm{Bu}, \mathrm{DMSO}$ & 84
\end{tabular}

${ }^{a}$ The reaction was carried out under $\mathrm{N}_{2}$ atmosphere using 1a (1 equiv, $0.1 \mathrm{mmol}$ ) and base in $1 \mathrm{~mL}$ of solvent, and the mixture was protected from light with aluminum foil. ${ }^{b}$ Yields were quantified by gas chromatography (GC) using internal standard method. ${ }^{c}$ Isolated yield.

the reaction was carried out in DMF for $1 \mathrm{~h}$, using three equivalents of $\mathrm{KO}^{t} \mathrm{Bu}$ at $\mathrm{rt}$ (Table 1, entry 1). Notably, yield was increased to $96 \%$ when DMSO was employed as a solvent (entry 2). A variety of solvents revealed that the reaction media had a significant impact on the reaction efficiency. THF and ethanol did not work well for this desulfonylation process, and $2 \mathrm{a}$ was obtained in $26 \%$ yield and traces, respectively, after $1 \mathrm{~h}$ (entries 3 and 4). Incomplete conversion was observed when the amount of $\mathrm{KO}^{t} \mathrm{Bu}$ was lowered (entry 5). Base effect was also examined (entries 6-11), showing that the reaction did not work using $\mathrm{K}_{2} \mathrm{CO}_{3}, \mathrm{Cs}_{2} \mathrm{CO}_{3}$ or $\mathrm{KOH}$ at $\mathrm{rt}$ and only $12 \%$ yield of $2 \mathrm{a}$ was obtained when the reaction was carried out with $\mathrm{KOH}$ at $65{ }^{\circ} \mathrm{C} .{ }^{13}$ Moreover, 21 and $84 \%$ yields of 2 a were obtained when other bases such as $\mathrm{NaH}$ and $\mathrm{NaO}^{t} \mathrm{Bu}$ were employed. This environmentally friendly methodology avoided the use of transition-metal ${ }^{56}$ or phasetransfer catalysts, ${ }^{15}$ toxic solvents, and high-temperature conditions. $^{13}$

Once optimal reaction conditions were determined, several heterocycles were deprotected using only $\mathrm{KO}^{t} \mathrm{Bu}$ in DMSO at rt. The results are shown in Table 2. A complete $\mathrm{N}$ desulfonylation of $N$-tosyl 7 -azaindole $(\mathbf{1 b})$, benzotriazole (1c), and pyrrole (1d) was achieved after $1 \mathrm{~h}$ (entries 1-3), whereas only $47 \%$ yield of carbazole was obtained under identical conditions (entry 4). Other sulfonyl-protecting groups were tested, such as benzenesulfonyl, 2-chlorobenzenesulfonyl and 2-nitrobenzenesulfonyl (o-Ns) groups (substrates $\mathbf{1 f}-\mathbf{h})$, and desulfonylated product $\mathbf{2 a}$ was also obtained in very good yields (entries 5-7). Additionally, desulfonylation reaction of compound 1f was carried out at higher concentrations to demonstrate the practical utility of this methodology. Product 2a was successfully obtained without a decrease in the isolated yield when $0.5 \mathrm{mmol}$ of 
Table 2. N-Desulfonylation of Indoles and Related Heterocycles $^{a}$

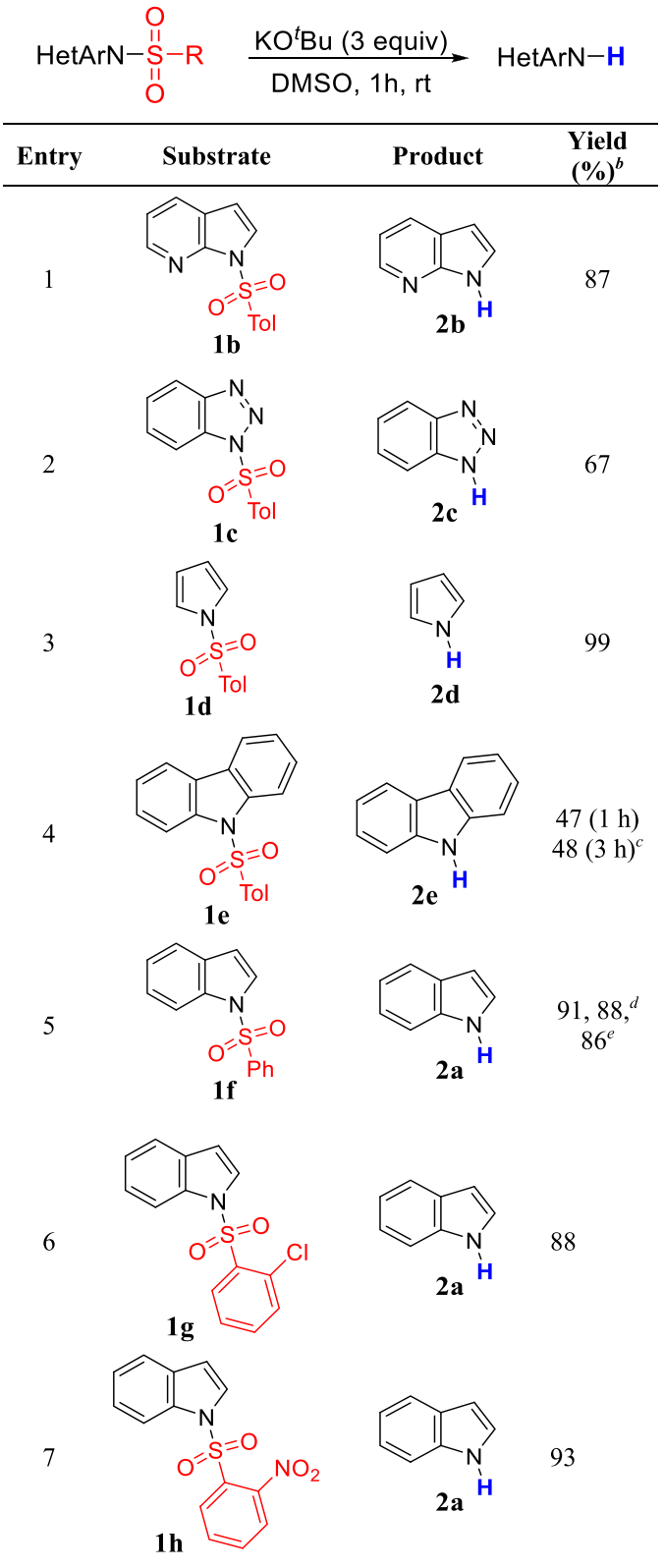

${ }^{a}$ The reaction was carried out under $\mathrm{N}_{2}$ atmosphere using $\mathbf{1}$ ( 1 equiv, $0.1 \mathrm{mmol}$ ) and $\mathrm{KO}^{t} \mathrm{Bu}$ ( 3 equiv) in DMSO $(1 \mathrm{~mL})$, and the mixture was protected from light with aluminum foil. ${ }^{b}$ Isolated yields after column chromatography. ${ }^{c} N$-Tosylcarbazole $(1 \mathbf{e})$ was recuperated in $50 \%$ yield. ${ }^{d}$ Reaction carried out 5 times more concentrated $(0.5$ mmol of $\mathbf{1 f}$ in $1 \mathrm{~mL}$ of DMSO). ${ }^{e}$ Reaction carried out starting from 1 $\mathrm{g}$ of $\mathbf{1 f}$ in $7.8 \mathrm{~mL}$.

1f in DMSO was employed or even when the reaction was scaled up to $1 \mathrm{~g}$ ( $3.9 \mathrm{mmol}$, entry 5).

Next, our attention was focused on the scope of this desulfonylation process to deprotect different $\mathrm{N}$-arylsulfonamides and phenyl benzenesulfonates. For instance, $\mathrm{N}, \mathrm{N}$ diphenyl tosylamine (1i) was chosen as a representative derivative of aromatic $p$-toluenesulfonamides, giving the desufonylted product $2 \mathbf{i}$ in $72 \%$ yield (Table 3, entry 1 ). However, $N, N$-diphenyl benzenesulfonamide (1j) and unsubstituted or $N$-methylsubstituted aromatic sulfonamides (1/k
Table 3. N-Detosylation of Amino and Sulfonate Moieties ${ }^{a}$

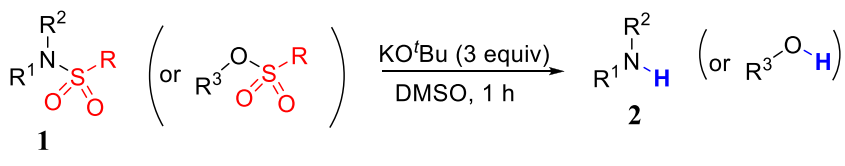

Estry (\%)

${ }^{a}$ The reaction was carried out under $\mathrm{N}_{2}$ atmosphere using 1 ( 1 equiv, $0.1 \mathrm{mmol}$ ) and $\mathrm{KO}^{t} \mathrm{Bu}$ ( 3 equiv) in DMSO $(1 \mathrm{~mL})$, and the mixture was protected from light with aluminum foil. ${ }^{b}$ Yields were quantified by GC using internal standard method. ${ }^{c}$ Isolated yield. ${ }^{d}$ Using 5 equiv of $\mathrm{KO}^{t} \mathrm{Bu}$ for $3 \mathrm{~h}$.

and 11) did not give the corresponding products $\mathbf{2 i}, \mathbf{2 k}$, or $\mathbf{2 l}$ (Table 3, entries 2-4). These results led us to explore the possibility of carrying out selectively the removal of $p$ toluenesulfonyl group. In this way, the polytosylated substrate $1 \mathbf{m}$ was tested and benzenesulfonate moiety could be selectively deprotected in the presence of $p$-toluenesulfonamide moiety, giving $\mathbf{2 m}$ in moderate isolated yield (entry 5 ). There are a few examples of removing sulfonyl groups from sulfonates, such as $\mathrm{KOH}$ in refluxing $\mathrm{MeOH},{ }^{75} \mathrm{KOH}$ with ${ }^{t} \mathrm{BuOH}$ in toluene at $100{ }^{\circ} \mathrm{C},{ }^{76} n$-PrSLi in hexamethylphosphoramide (HMPA) at $180{ }^{\circ} \mathrm{C},{ }^{77}$ or using photochemical process via PET. $^{78,79}$ Thus, other benzenesulfonate substrates 
were studied following our protocol, such as 4-methoxyphenyl 4-methylbenzenesulfonate (1n), 4-cyanophenyl 4-methylbenzenesulfonate (10), 2-iodophenyl 4-methylbenzenesulfonate (1p), and 2-iodophenyl benzenesulfonate (1q), giving the corresponding phenols $\mathbf{2 n - p}$ in very good yields (74-89\%) and using only $\mathrm{KO}^{t} \mathrm{Bu}$ in DMSO at rt.

A plausible mechanism for the desulfonylation reaction, which is consistent with the observations described above, is shown in Scheme 1. Although the $\mathrm{p} K_{\mathrm{a}}$ (methyl group) of

\section{Scheme 1. Possible Mechanism of N-Detosylation}

\section{Reactions in Basic Medium}

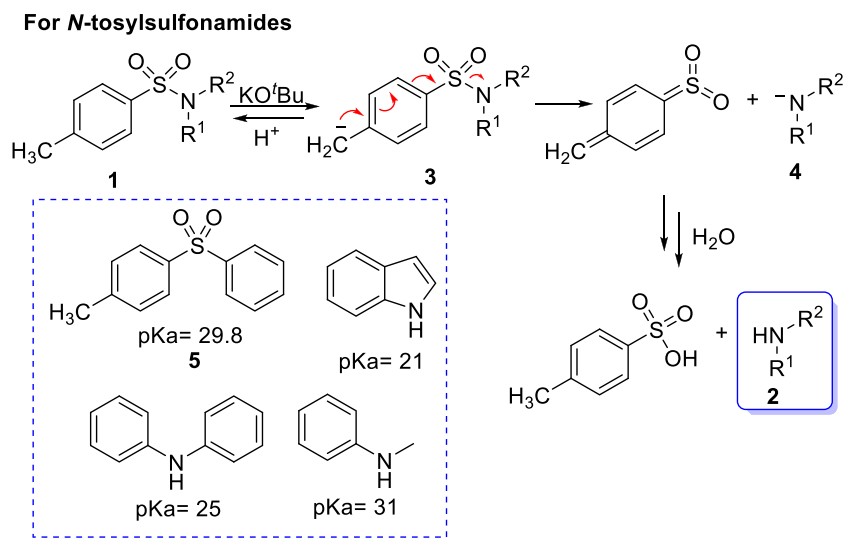

toluenesulfonamide is unknown, it can be approximated to that of 1-methyl-4-(phenylsulfonyl)benzene (5), whose $\mathrm{p} K_{\mathrm{a}}$ is $29.8^{80}$ in DMSO. Therefore, the $N$-tosylsulfonamide forms the corresponding anion 3 in the presence of $\mathrm{KO}^{t} \mathrm{Bu}\left({ }^{t} \mathrm{BuOH}, \mathrm{p} K_{\mathrm{a}}\right.$ $=32.2){ }^{81}$ which was indicated by the observation that the solution turned blue. The $\mathrm{N}-\mathrm{S}$ bond of anion 3 could fragment to produce amide anion 4 , which after protonation finally gives the deprotected product 2 . This fragmentation is thermodynamically controlled by the acidity $\left(\mathrm{p} K_{\mathrm{a}}\right.$ value) of the final deprotected product 2 . Since the conjugate base of compound 5 is more basic than those of indole $\left(\mathrm{p} K_{\mathrm{a}}=21.0\right.$ in DMSO $)^{82}$ and diphenylamine $\left(\mathrm{pK}_{\mathrm{a}}=25.0\right.$ in DMSO $){ }^{83}$ this process is favored for $N$-tosyl indole (1a) and diphenyl $N$ tosylamine (1i). Meanwhile, for $N$-methyl- $N$-phenyltosylamine (11), this fragmentation does not take place due to the higher $\mathrm{p} K_{\mathrm{a}}$ value for $N$-methyl- $N$-phenylamine $\left(\mathrm{p} K_{\mathrm{a}}=30.6\right.$ for aniline in DMSO). ${ }^{83}$

A different mechanism for the deprotection of $\mathrm{N}$ benzenesulfonamides is proposed, involving a direct attack of the base to the sulfur atom (Scheme 2). This behavior explains the reactivity of $\mathbf{1} \mathbf{f}-\mathbf{h}$ with phenyl, 2-chlorophenyl, and 2-nitrophenyl as substituents. This mechanism could also explain the lack of reactivity for $\mathrm{N}, \mathrm{N}$-diphenyl benzenesulfonamide (1j) due to a high steric hindrance for the nucleophilic attack of the base.

To demonstrate the presence of a polar mechanism, the reaction of 1 a was quenched with benzyl bromide and benzyl indole (2q) was obtained in quantitative isolated yield (eq 1). In addition, the reaction of $1 \mathrm{a}$ with $\mathrm{KO}^{t} \mathrm{Bu}$ was carried out in the presence of 2,2,6,6-tetramethyl-1-piperidinyloxy (TEMPO) as a radical-trapping agent, and a similar yield of 2a was obtained ( $87 \%$ yield), indicating the absence of radicals as intermediates (eq 2).

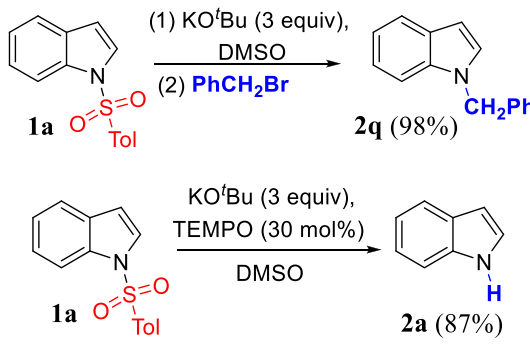

Regarding the lack of reactivity of $\mathbf{1 j}$ and $\mathbf{1 l}$ substrates under the proposed polar mechanism (Table 3, entries 2 and 4), we decided to explore PET for $\mathrm{N}$-desulfonylation reactions. As dimsyl anion is able to form aryl and alkyl radicals from RX under visible light irradiation, ${ }^{84,85}$ we carried out the reaction for substrate $\mathbf{1 j}$ with $\mathrm{KO}^{t} \mathrm{Bu}$ in DMSO under irradiation using UV-vis lamps $(\lambda>350 \mathrm{~nm})$ for $3 \mathrm{~h}$ giving the desulfonylation product $2 \mathbf{i}$ in $65 \%$ yield (Table 4 , entry 1 ). Moreover, product $\mathbf{2 i}$ was obtained in $88 \%$ yield when UVvis lamps were replaced by using $3 \mathrm{~W}$ blue light-emitting diodes (LEDs) (entry 2). To rule out homolytic fragmentation, a photoinduced reaction was performed in the absence of base and substrate $\mathbf{1 j}$ was recovered in quantitative yield (entry 3). When the same conditions were applied to substrate 1r, the desulfonylated product $\mathbf{2 1}$ was given in only $20 \%$ yield (entry 4 ). Probably, the reduction potential of the excited dimsyl anion (unknown) could not achieve the ET to initiate the reaction. As some anions of substituted dihydro ethyl benzoates and quinoline previously prepared in liquid ammonia have been used as hydrogen donors in reductive reactions, ${ }^{86,87}$ we proposed $\mathrm{HE}$ anion as both an electron and hydrogen atom donor to promote the desulfonylation reaction of $N$-methyl- $N$-arylsulfonamides as an alternative strategy to $\left[\operatorname{Ir}(\mathrm{ppy})_{2}(\mathrm{dtb}-\mathrm{bpy}) \mathrm{PF}_{6}\right] / \mathrm{HE}^{52}$ and $\mathrm{Cu}$ complex/HE. ${ }^{55}$

Therefore, the reaction of $1 \mathrm{r}$ with 1 equiv of $\mathrm{HE}$ and 1.1 equiv of $\mathrm{KO}^{t} \mathrm{Bu}$ for $17 \mathrm{~h}$ using blue LED afforded product $\mathbf{2 l}$ in $46 \%$ yield (Table 4 , entry 5 ). Furthermore, a higher yield was observed when the reaction was carried out employing 2.2 equiv of $\mathrm{KO}^{t} \mathrm{Bu}$ ( $73 \%$ of 21 , entry 6 ). Notably, the yield was increased to 79 and $88 \%$ when higher amounts of HE (1.3 and 1.5 equiv) were used (entries 7 and 8). Finally, product 1r was obtained in $98 \%$ yield when 2 equiv of $\mathrm{HE}$ were employed (entry 9). No reaction is detected under dark conditions (entry 10) discarding a spontaneous ET or polar mechanism. Moreover, a similar yield of 21 was given when the reaction was carried out in $1 \mathrm{~h}$, reducing considerably the reaction time (entry 11 ). No product 21 was obtained in the absence of base (entry 12) or when other bases and reducing reagents such as $\mathrm{NEt}_{3}$ or $\mathrm{N}$-ethyldiisopropylamine (DIPEA)

\section{Scheme 2. Possible Reaction Mechanism for Deprotection of N-Benzenesulfonamides}

For $\boldsymbol{N}$-benzenesulfonamides

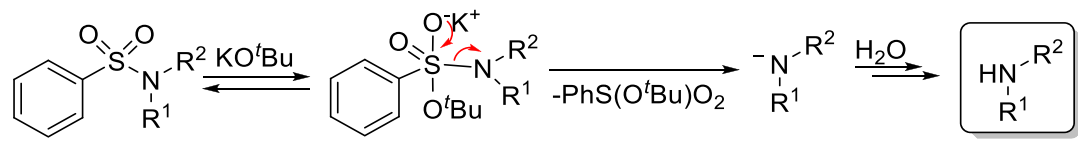


Table 4. Photodesulfonylation of $1 \mathrm{j}$ and $1 \mathrm{r}$ in $\mathrm{DMSO}^{a}$

\begin{tabular}{|c|c|c|c|c|}
\hline & & $\underset{\substack{\text { Blue-LED } \\
\text { DMSO, } \mathrm{rt}}}{\stackrel{\mathrm{R}^{1}}{{ }^{\mathrm{R}}}{ }^{\mathrm{R}}}$ & & \\
\hline Entry & Substrate & Conditions & Time (h) & Yield $^{b}$ \\
\hline $1^{c}$ & $\mathbf{1 j}$ & $\mathrm{h} v(\lambda>350 \mathrm{~nm}), \mathrm{KO}^{t} \mathrm{Bu}(3$ equiv $)$ & 3 & $2 \mathbf{i}, 65$ \\
\hline 2 & $\mathbf{1 j}$ & $\mathrm{KO}^{t} \mathrm{Bu}$ (3 equiv) & 3 & $2 \mathbf{i}, 88$ \\
\hline 3 & $\mathbf{1 j}$ & Without base & 3 & $2 \mathbf{i},--$ \\
\hline 4 & $1 \mathbf{r}$ & $\mathrm{KO}^{t} \mathrm{Bu}$ (3 equiv) & 1 & $2 \mathbf{l}, 20$ \\
\hline 5 & 1r & $\mathrm{HE}$ ( 1 equiv), $\mathrm{KO}^{t} \mathrm{Bu}$ (1.1 equiv) & 17 & 2l, 46 \\
\hline 6 & 1r & $\mathrm{HE}$ ( 1 equiv), $\mathrm{KO}^{t} \mathrm{Bu}$ ( 2.2 equiv) & 17 & 21,73 \\
\hline 7 & $1 \mathbf{r}$ & $\mathrm{HE}$ (1.3 equiv), $\mathrm{KO}^{t} \mathrm{Bu}$ ( 2.2 equiv) & 17 & 21, 79 \\
\hline 8 & $1 \mathbf{r}$ & $\mathrm{HE}$ ( 1.5 equiv), $\mathrm{KO}^{t} \mathrm{Bu}$ ( 2.2 equiv) & 17 & 21, 88 \\
\hline 9 & $1 \mathbf{r}$ & $\mathrm{HE}$ ( 2 equiv), $\mathrm{KO}^{t} \mathrm{Bu}$ ( 2.2 equiv) & 17 & $\begin{array}{r}\text { 21, } 98 \\
(95)^{d}\end{array}$ \\
\hline 10 & 1r & Dark, $\mathrm{HE}$ ( 2 equiv), $\mathrm{KO}^{t} \mathrm{Bu}$ (2.2 equiv) & 17 & $21,--$ \\
\hline 11 & 1r & $\mathrm{HE}$ ( 2 equiv), $\mathrm{KO}^{t} \mathrm{Bu}$ (2.2 equiv) & 1 & 21, 98 \\
\hline 12 & 1r & HE ( 2 equiv) & 1 & $21,--$ \\
\hline 13 & 1r & DIPEA (2 equiv) & 1 & $21,--$ \\
\hline 14 & 1r & $\mathrm{NEt}_{3}$ (2 equiv) & 1 & $21,--$ \\
\hline 15 & $1 \mathbf{r}$ & 1,1-diphenylethene ( 0.5 equiv), & 1 & 21,77 \\
\hline 16 & $1 \mathbf{r}$ & $\begin{array}{l}\text { TEMPO ( } 30 \text { mol } \%) \text {, HE ( } 2 \text { equiv), } \\
\mathrm{KO}^{t} \mathrm{Bu}(2.2 \text { equiv) }\end{array}$ & 1 & 21,68 \\
\hline
\end{tabular}

${ }^{a}$ Unless otherwise noted, the photostimulated reaction conditions were established under $\mathrm{N}_{2}$ atmosphere using 1 ( 1 equiv, $0.1 \mathrm{mmol}$ ), base, and/or additive in DMSO $(1 \mathrm{~mL})$ with blue LED $(3 \mathrm{~W})$ in a sealed tube. ${ }^{b}$ Yields were quantified by GC using the internal standard method. ${ }^{c}$ Irradiation was conducted in a photochemical reactor equipped with two HPIT $400 \mathrm{~W}$ lamps $(\lambda \geq 350 \mathrm{~nm})$. ${ }^{d}$ Isolated yield.

were used as control experiments (entries 13 and 14). Finally, the desulfonylation was carried out in the presence of TEMPO and 1,1-diphenylethylene as radical scavengers and the reaction was partially inhibited (entries 15 and 16). We suggest that radical formation could be involved in the key step of this mechanism (Scheme 3).

A proposed mechanism for photoinduced $\mathrm{N}$-desulfonylation reaction in the presence of $\mathrm{HE}$ anion is shown in Scheme 3. $\mathrm{HE}$ anion is easily prepared in situ by reaction of $\mathrm{HE}$ with $\mathrm{KO}^{t} \mathrm{Bu}$ in $\mathrm{DMSO}$ as a solvent. Anion formation is rapidly detected due to the color of the solution (orange), indicating that the $\mathrm{HE}$ anion is the visible-light-absorbing reagent $\left(\lambda_{\max }=\right.$ $475 \mathrm{~nm}) .{ }^{88}$ After irradiation, ET occurs between the photoexcited $\mathrm{HE}$ anion and $\mathrm{N}$-methylarylsulfonylamine $\mathbf{1}$, forming the corresponding radical anion of the substrate (initial step) and HE radical. The $\mathrm{N}-\mathrm{S}$ bond cleavage in these radical anions can generate either $\mathrm{N}$-centered anions or radicals depending on the nature of the $\mathrm{N}$-substituent. It is known that $N$-tosyl-N,N-phenylamine (1i) and $N$-benzyl- $N$ - phenyl $p$-toluenesulfonamide fragments to give aminyl radicals $\left(\mathrm{Ph}_{2} \mathrm{~N}^{\bullet} \text { and } \mathrm{Ph}(\mathrm{Bn}) \mathrm{N}^{\bullet}\right)^{43,53}$ and sulfonate anions $\left(\mathrm{TolSO}_{2}{ }^{-}\right)$ (step 1). A fast hydrogen transfer from the $\mathrm{HE}$ anion to aminyl radical affords product $\mathbf{2}$ and the $\mathrm{HE}$ radical anion. Alternatively, sulfonate anion can deprotonate $\mathrm{HE}$ radical to give the corresponding HE radical anion and sulfonic acid. The driving force for this reaction is the rearomatization of the $\mathrm{HE}$ anion (or $\mathrm{HE}$ radical) to give the $\mathrm{HE}$ radical anion (step 2). Following, ET from the HE radical anion to 1 gives a pyridine derivative and $\mathrm{N}$-methylarylsulfonylamides radical anion to continue the radical chain process (step 3). Finally, the intermediate aminyl radical can generate the reductive product 2 , removing a hydrogen from the $\mathrm{HE}$ radical (final step).

Next, several $N$-methyl- $N$-arylsulfonamides (11 and $\mathbf{1 s - a b )}$ were examined under the same photoinduced conditions in the presence of HE anion (Table 5). Desulfonylation reaction exhibited high functional group tolerance and yields. For ortho- or para-substituted sulfonamides with electron-donat- 
Scheme 3. Proposed Photodesulfonylation Reaction Mechanism Using HE Anion as Visible-Light-Absorbing Reagent and Electron and Hydrogen Atom Donor

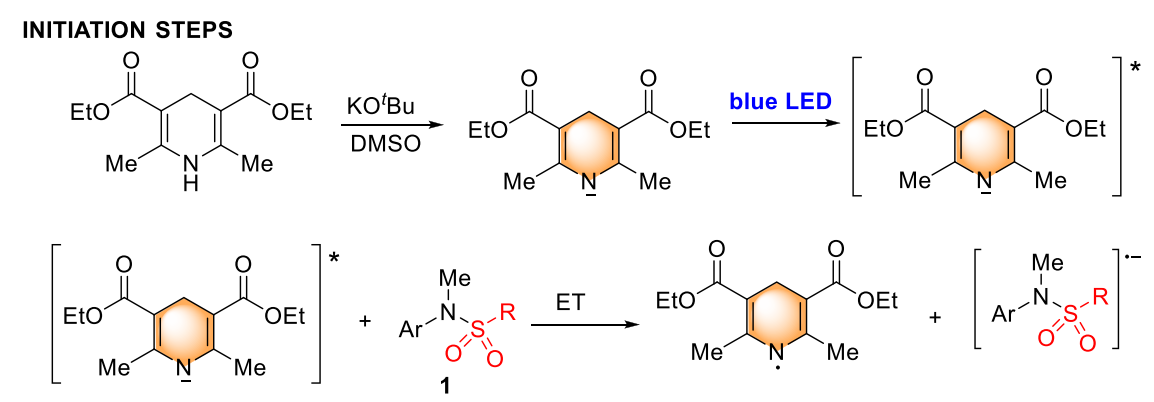

\section{PROPAGATION STEPS}

Step 1: Fragmentation

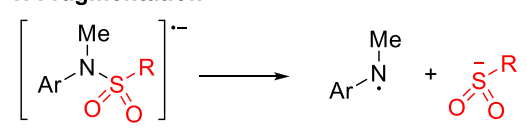

Step 2: HE radical anion formation

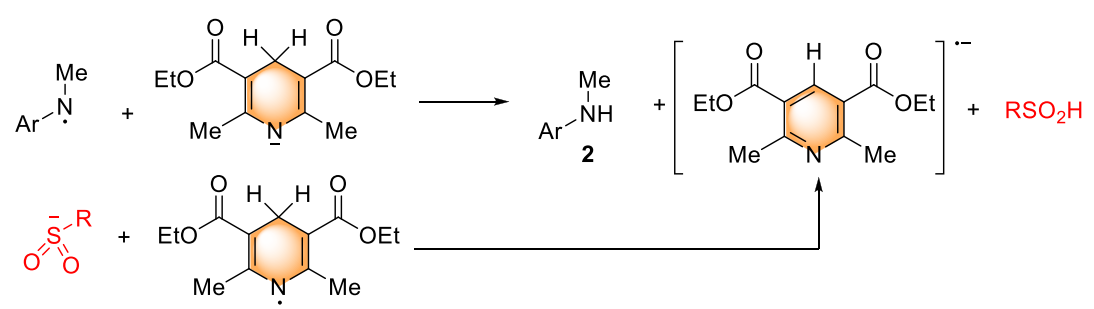

Step 3: Electron Transfer

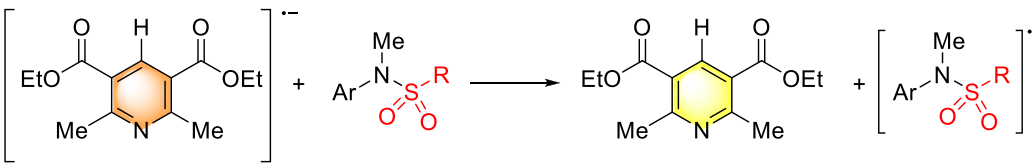

FINAL STEPS

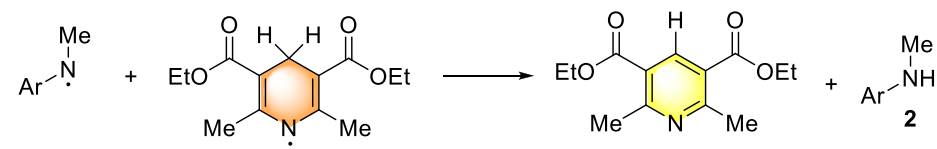

ing and electron-withdrawing groups, the reaction gives the desired products in regular to excellent yields (37-98\% yields, entries 1-11). Furthermore, similar yields were also obtained if tosyl- or benzenesulfonyl-protecting groups were used.

For $N$-(4-iodophenyl)- $N$-methylbenzenesulfonamide (1aa, Table 5, entry 10), the dehalogented product 21 was obtained as the main product. Regarding this result and the mechanism presented in Scheme 4, the formation of radical anion $\mathbf{1} \mathbf{a a}^{\bullet-}$ as an intermediate is proposed (Scheme 4). This radical anion has two possible reaction pathways. First, a $\mathrm{C}-\mathrm{I}$ bond fragmentation may occur to give radical 6 , which after reduction affords intermediate 7 (path A). This intermediate can also react with $\mathrm{HE}$ anion under photostimulated conditions to finally yield the product 21 . The other possibility is a $\mathrm{N}-\mathrm{S}$ bond fragmentation to give anion 8 , which finally provides product 9 with retention of iodine atom (path B). In this case, path B was discarded because 9 was not detected. This result suggests that $\mathrm{C}-\mathrm{I}$ fragmentation rate giving radical 6 is faster than $\mathrm{N}-\mathrm{S}$ fragmentation to give 9. Furthermore, it confirms the presence of radical anions as intermediates in the proposed photoinduced reaction (Scheme 3). Otherwise, C-I fragmentation was not observed for substrates $\mathbf{1 p}$ and $\mathbf{1 q}$ in the first approach $\left(\mathrm{KO}^{t} \mathrm{Bu}\right.$ in DMSO at rt; Table 3, entries 8 and 9), showing an important difference between both examined mechanisms.

PET also provides an alternative route for dehalogenation reactions. In recent years, $\mathrm{Pd},{ }^{89} \mathrm{Ir},{ }^{90} \mathrm{Cu},{ }^{91} \mathrm{Pt}$ complex, ${ }^{92}$ and $\mathrm{Ni}$ supported on carbon nitride ${ }^{89}$ have been used to undergo reductions of aryl halides under visible light irradiation. Particularly, dehalogenation and aryl radical generation could also be achieved using many visible light organic photoreductants $^{93-95}$ or photocatalyts. ${ }^{96-102}$ To further explore our visible-light-promoted method, reduction reaction of aryl or heteroaryl halides in the presence of $\mathrm{HE}$ anion was studied. As shown in Table 6, aryl chloride, bromide, and iodide derivatives are dehalogenated (entries 1-10) in good to excellent yields under visible light irradiation using $\mathrm{HE}$ anion as electron and hydrogen atom donor. We finally suggest that the oxidation potential of the photoexcited $\mathrm{HE}$ anion $\left(E_{\mathrm{oxHE}}{ }^{*} / \mathrm{HE}^{-}=-2.490 \mathrm{~V}\right)^{103}$ is higher than that of the photoexcited dimsyl anion, which does not effectively reduce aryl bromides or chlorides. ${ }^{84,85}$ 
Table 5. Substrate Scope Examination of Photodesulfonylation Reaction ${ }^{a}$

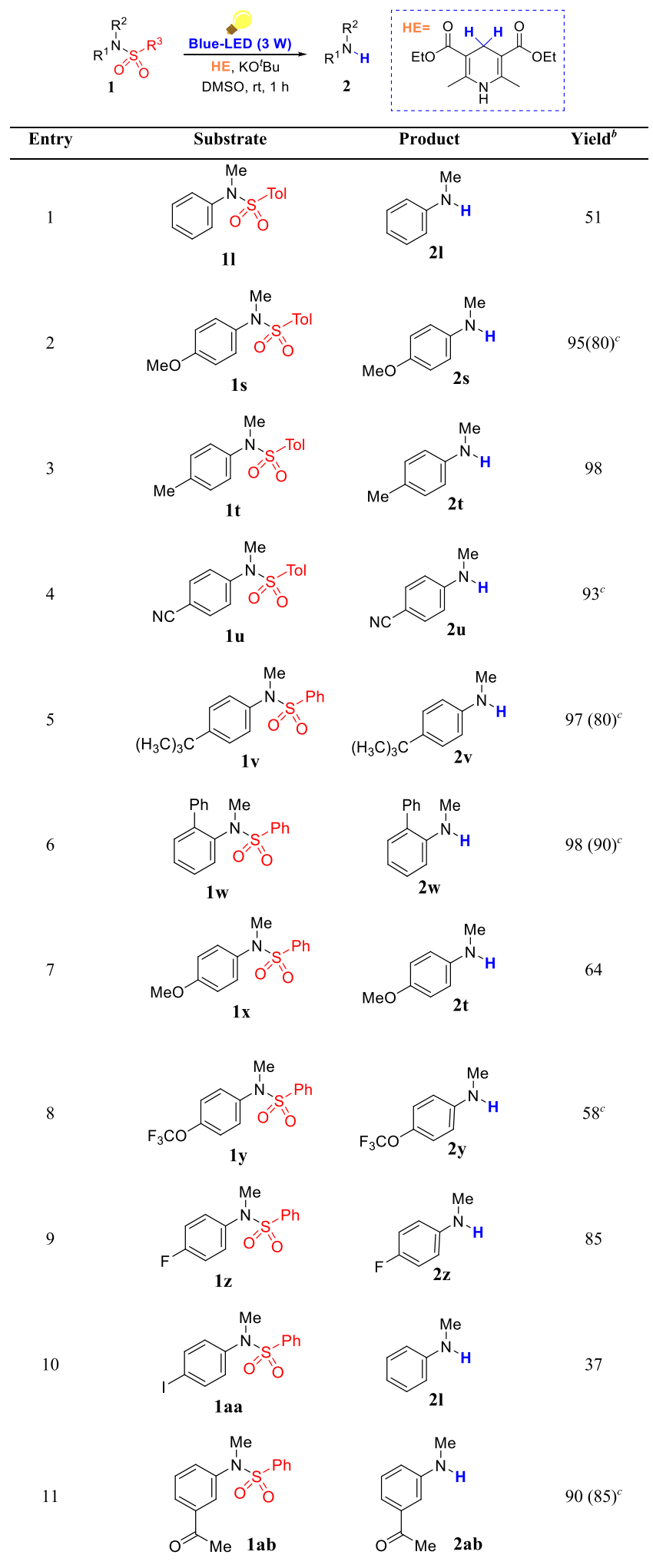

${ }^{a}$ The photostimulated reaction was carried out under $\mathrm{N}_{2}$ atmosphere using 1 ( 1 equiv, $0.1 \mathrm{mmol}$ ), $\mathrm{HE}$ ( 2 equiv), and $\mathrm{KO}^{t} \mathrm{Bu}$ (2.2 equiv) in DMSO ( $1 \mathrm{~mL}$ ) using $3 \mathrm{~W}$ blue LED, at $\mathrm{rt}$ in a sealed tube. ${ }^{b}$ Yields were quantified by GC using internal standard method. ${ }^{c}$ Isolated yields.

\section{CONCLUSIONS}

To summarize, in this work, we presented two green synthetic methodologies toward the desulfonylation process under transition-metal-free and $\mathrm{rt}$ conditions. The first methodology proceeds under mild reaction conditions using only $\mathrm{KO}^{t} \mathrm{Bu}$ in DMSO at rt, where a variety of $N$-sulfonyl heterocycles and phenyl benzenesulfonates were effectively deprotected. This strategy involves a polar mechanism very sensitive to both electronic and steric effects. The second methodology involves a visible-light-promoted method utilizing $\mathrm{HE}$ anion as electron and hydrogen atom donor and blue LED as a light source. In this way, several $N$-methyl- $N$-arylsulfonamides have given the corresponding products in good to excellent yields. Furthermore, the reaction was highly tolerant to a variety of functional groups and was successfully scaled up to $1 \mathrm{~g}$. Moreover, this methodology was also expanded to aryl halides substrates and it is noteworthy that even the $\mathrm{ArCl}$ reacts giving $\mathrm{ArH}$ with good yields. $\mathrm{HE}$ anion as visible-lightabsorbing reagent does not require previous preparation and is a convenient alternative to expensive transition-metal photocatalysts.

\section{EXPERIMENTAL SECTION}

General Methods. Purification of desired compounds was done by column chromatography on silica gel. Gas chromatographic (GC) analysis was performed with a flame ionization detector, on a $30 \mathrm{~m}$ capillary column of film thickness $0.32 \mathrm{~mm} \times 0.25 \mu \mathrm{m}$, with a $5 \%$ phenylpolysiloxane phase. Gas chromatography/mass spectroscopy (GC/MS) analysis was performed employing an electronic impact (EI) ionization method and a $25 \mathrm{~m} \times 0.2 \mathrm{~mm} \times 0.33 \mu \mathrm{m}$ column with a $5 \%$ phenylpolysiloxane phase. ${ }^{1} \mathrm{H}$ NMR and ${ }^{13} \mathrm{C} \operatorname{NMR}\left\{{ }^{1} \mathrm{H}\right\}$ spectra were recorded on 400 and $500 \mathrm{MHz}$ in spectrometers with $\mathrm{CDCl}_{3}$ or acetone- $d_{6}$ as solvent and tetramethylsilane (TMS) as internal standard. Additional ${ }^{19} \mathrm{~F}$ NMR spectra were recorded for fluorinated compounds using a $377 \mathrm{MHz}$ spectrometer, with $\mathrm{CDCl}_{3}$, acetone- $d_{6}\left(\mathrm{CD}_{3} \mathrm{COCD}_{3}\right)$, or DMSO- $d_{6}\left(\mathrm{CD}_{3} \mathrm{~S}(\mathrm{O}) \mathrm{CD}_{3}\right)$ as solvents. Coupling constants are given in hertz $(\mathrm{Hz})$, and chemical shifts are reported in $\delta$ values in parts per million (ppm). Data are reported as follows: chemical shift, multiplicity $(\mathrm{s}=$ singlet, $\mathrm{s}$ br $=$ broad singlet, $\mathrm{d}=$ doublet, $\mathrm{t}=$ triplet, $\mathrm{dd}=$ double doublet, $\mathrm{dt}=$ double triplet, $\mathrm{ddd}$ = double double doublet, $\mathrm{m}=$ multiplet $)$, coupling constants $(\mathrm{Hz})$, and integration. All new products were further characterized by twodimensional (2D) NMR techniques $\left({ }^{1} \mathrm{H} /{ }^{1} \mathrm{H}\right.$ correlation spectroscopy (COSY), ${ }^{1} \mathrm{H} /{ }^{13} \mathrm{C}$ heteronuclear single-quantum coherence (HSQC), and ${ }^{1} \mathrm{H} /{ }^{13} \mathrm{C}$ heteronuclear multiple-bond correlation spectroscopy (HMBC)) and high-resolution mass spectrometry (HRMS). HRMS analyses were carried out using a time-of-flight mass spectrometry (TOF-MS) instrument with an electrospray ionization (ESI) source. Photoinduced reactions were conducted with blue LED $(\lambda=465 \pm$ $20 \mathrm{~nm})$ at $3 \mathrm{~W}$ of potency and $700 \mathrm{mV}$ of current emission spectra (Figure S1) and HPIT $400 \mathrm{~W}$ lamps $(\lambda \geq 350 \mathrm{~nm}$, Figure S2). The apparatus and irradiation setup are shown in Figure $S 3$.

Materials. $1 H$-Indole (2a), $1 H$-pyrrolo[2,3-b]pyridine (2b), $1 H$ benzo[d][1,2,3]triazole (2c), $1 H$-pyrrole (2d), 9H-carbazole (2e), $\mathrm{N}, \mathrm{N}$-diphenylamine (2i), 4-methoxyphenol (2n), 4-hydroxybenzonitrile (2o), 2-iodophenol (2p), aniline, benzyl bromide, 4-methoxyaniline, 4-methylaniline, 4-aminobenzonitrile, 4-(tert-butyl)-aniline, [1,1'-biphenyl]-2-amine, 4-(trifluoromethoxy)aniline, 4-fluoroaniline, 4-iodoaniline, 4-aminophenol, 3-aminoacetophenone, benzenesulfonyl chloride, 2-chlorobenzenesulfonyl chloride, 2-nitrobenzenesulfonyl chloride, 2-iodonaphthalene (10a), 1-bromonaphthalene (10b), 1chloronaphthalene (10c), 9-bromoanthracene (10d), 9-bromophenanthrene (10e), 4-bromo-1,1'-biphenyl (10f), 3-iodopyridine $(\mathbf{1 0 g})$, 2-chloropyridine (10h), 4-bromobenzonitrile (10i), 4-chlorobenzonitrile $(\mathbf{1 0 j})$, naphthalene (11a), anthracene (11d), phenanthrene (11e), biphenyl (11f), pyridine $(\mathbf{1 1 g})$, cyanobenzene $(11 \mathrm{i}), \mathrm{KO}^{t} \mathrm{Bu}$, $\mathrm{NaO}^{t} \mathrm{Bu}, \mathrm{K}_{2} \mathrm{CO}_{3}, \mathrm{Cs}_{2} \mathrm{CO}_{3}, \mathrm{KOH}, \mathrm{NaOH}, \mathrm{NaH}$ (60\% in mineral oil), 
Scheme 4. Possible Fragmentations of Radical Anion 1aa ${ }^{\bullet-}$<smiles>CN(c1ccc(S(=O)(=O)N(C)c2ccc(I)cc2)cc1)S(=O)(=O)c1ccccc1</smiles>

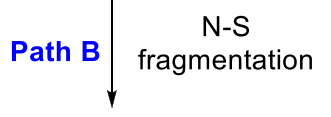<smiles>[N-][N+]([O-])c1ccc(I)cc1</smiles><smiles>CNc1ccc(I)cc1</smiles><smiles>CCCCNc1ccccc1NCC</smiles>

9 (not observed)

$\mathrm{NH}_{4} \mathrm{NO}_{3}, \mathrm{NH}_{4} \mathrm{Cl}$, tetrabutylammonium hydrogen sulfate, $\mathrm{Na}_{2} \mathrm{SO}_{4}$, 2,2,6,6-tetramethyl-1-piperidinyloxy (TEMPO), Hantzsch ester, $\mathrm{NEt}_{3}$, DIPEA, 1,1-diphenyl ethene, and pyridine were purchased from commercial suppliers and used without further purification. DMSO, DMF, THF, $\mathrm{CH}_{2} \mathrm{Cl}_{2}$, and toluene were distilled and dried under molecular sieves $(3 \AA)$. All solvents were of analytical grade. The silica used in column chromatography corresponds to silica gel $60(0.063-0.200 \mathrm{~mm})$.

Typical Procedures for Synthesis of Sulfonamides. Method $A$. The reaction was carried out in a Schlenk tube equipped with an inert $\mathrm{N}_{2}$ inlet and magnetically stirred at rt. In the Schlenk tube, $\operatorname{DMSO}(5 \mathrm{~mL})$ was dried and deoxygenated, $\mathrm{KO}^{t} \mathrm{Bu}$ (1.0 equiv, 112 $\mathrm{mg}, 1 \mathrm{mmol}$ ) was added, and the mixture was protected from light with aluminum foil. Then, the corresponding NH-heterocycle or aniline ( 1 equiv, $1 \mathrm{mmol}$ ) and benzenesulfonyl chloride (1.2 equiv, $1.2 \mathrm{mmol}$ ) were added and the reaction mixture was stirred overnight $(18 \mathrm{~h})$. After the reaction was finished, it was quenched with $\mathrm{NH}_{4} \mathrm{NO}_{3}$ or $\mathrm{NH}_{4} \mathrm{Cl}$ and water in excess and the residue was extracted with EtOAc or $\mathrm{CH}_{2} \mathrm{Cl}_{2}(3 \times 30 \mathrm{~mL})$, the organic layers extracted were combined, washed with water, dried with anhydrous $\mathrm{Na}_{2} \mathrm{SO}_{4}$, and concentrated under reduced pressure to leave the crude products. The reaction was analyzed with TLC, GC, and isolated with column chromatography over silica gel. (SI).

For details of methods B to E, see the Supporting Information

Characterization Data of Synthesized Sulfonamides. 1-[(2Chlorophenyl)sulfonyl]-1H-indole (1g). The title compound was obtained according to method B and was purified by column chromatography on silica gel eluting with hexane/EtOAc (90:10 $\rightarrow$ $80: 20)$. A light yellow solid was isolated in $71 \%$ yield $(0.71 \mathrm{mmol}$, $207 \mathrm{mg}$ ). ${ }^{1} \mathrm{H}$ NMR $\left(400 \mathrm{MHz}, \mathrm{CDCl}_{3}\right) \delta 8.15$ (dd, $J=8.2,1.8 \mathrm{~Hz}$, $1 \mathrm{H}), 7.74(\mathrm{~d}, J=3.7 \mathrm{~Hz}, 1 \mathrm{H}), 7.71-7.65(\mathrm{~m}, 1 \mathrm{H}), 7.60-7.54(\mathrm{~m}$, $1 \mathrm{H}), 7.51-7.39(\mathrm{~m}, 3 \mathrm{H}), 7.25-7.18(\mathrm{~m}, 2 \mathrm{H}), 6.67(\mathrm{~d}, J=3.7 \mathrm{~Hz}$, 1H). ${ }^{13} \mathrm{C} \mathrm{NMR}\left\{{ }^{1} \mathrm{H}\right\}\left(101 \mathrm{MHz}, \mathrm{CDCl}_{3}\right) \delta 136.4,134.8,134.5$, 132.9, 132.4, 131.2, 130.6, 127.9, 127.2, 124.3, 123.3, 121.5, 113.0, 107.5. ${ }^{1} \mathrm{H} /{ }^{1} \mathrm{H}$ COSY NMR $\left(400 \mathrm{MHz}, \mathrm{CDCl}_{3}\right) \delta_{\mathrm{H}} / \delta_{\mathrm{H}} 8.15 / 7.51-$ 7.39, 7.74/6.67, 7.71-7.65/7.60-7.54, 7.60-7.54/7.25-7.18, 7.517.39/7.51-7.39. ${ }^{1} \mathrm{H} /{ }^{13} \mathrm{C}$ HSQC NMR $\left(400 \mathrm{MHz}, \mathrm{CDCl}_{3}\right) \delta_{\mathrm{H}} / \delta_{\mathrm{C}}$ 8.15/131.4, 7.74/127.9, 7.71-7.65/113.0, 7.60-7.54/121.5, 7.51$7.39 / 134.8,7.51-7.39 / 132.4,7.51-7.39 / 127.2, \quad 7.25-7.18 / 123.3$, 7.25-7.18/124.3, 6.67/107.5. ${ }^{1} \mathrm{H} /{ }^{13} \mathrm{C}$ HMBC NMR (400 MHz, $\left.\mathrm{CDCl}_{3}\right) \delta_{\mathrm{H}} / \delta_{\mathrm{C}} 8.15 / 132.9,8.15 / 134.8,7.74 / 107.5,7.74 / 130.6,7.74 /$ $134.5,7.71-7.65 / 132.4,7.71-7.65 / 130.6,7.60-7.54 / 124.3,7.60-$ $7.54 / 134.5, \quad 7.51-7.39 / 127.2, \quad 7.51-7.39 / 131.2, \quad 7.51-7.39 / 132.4$, 7.51-7.39/132.9, 7.51-7.39/136.4, 7.25-7.18/113.0, 7.25-7.18/ $121.5,7.25-7.18 / 130.6,7.25-7.18 / 134.5,6.67 / 127.9,6.67 / 130.6$, 6.67/134.5. GC/MS EI $m / z 293\left(\mathrm{M}^{+}+2,9\right), 291\left(\mathrm{M}^{+}, 22\right), 117$ (10), 116 (100), 111 (27), 90 (11), 89 (61), 75 (35), 63 (37), 51 (10), 50 (17). HRMS (ESI) $m / z:[\mathrm{M}+\mathrm{H}]^{+}$calcd for $\mathrm{C}_{14} \mathrm{H}_{11} \mathrm{ClNO}_{2} \mathrm{~S}$ 292.0194; found 292.0189.
Methylation of Synthesized Sulfonamides (Method F). The reaction was carried out in a round-bottom flask equipped with a magnetic stirred bar. $\mathrm{KO}^{t} \mathrm{Bu}$ was added (1.1 equiv) to a solution of sulfonamide ( 1 equiv) in DMSO $(2 \mathrm{~mL})$; then, iodomethane (3 equiv) was slowly added. The resulting mixture was stirred at $\mathrm{rt}$ overnight. Water was added, the crude was extracted with EtOAc (3 $\times 30 \mathrm{~mL}$ ), and the layers were separated. The organic layers extracted were combined, washed with water, dried with anhydrous $\mathrm{Na}_{2} \mathrm{SO}_{4}$, and concentrated under reduced pressure to leave the crude products. The reaction was analyzed with thin-layer chromatography (TLC), GC, and isolated with column chromatography over silica gel.

$N$-(4-(tert-Butyl)phenyl)- $N$-methylbenzenesulfonamide (1v). $1 \mathbf{v}$ was obtained from $\mathbf{1 v}-\mathbf{s}$ and was purified by column chromatography on silica gel eluting with hexane/EtOAc $(95: 5 \rightarrow 80: 20)$. A colorless oil was isolated in $74 \%$ yield $(0.73 \mathrm{mmol}, 223 \mathrm{mg}) .{ }^{1} \mathrm{H}$ NMR (400 MHz, $\left.\mathrm{CDCl}_{3}\right) \delta 7.59-7.57(\mathrm{~m}, 3 \mathrm{H}), 7.46(\mathrm{t}, J=7.6 \mathrm{~Hz}$, $2 \mathrm{H}), 7.30(\mathrm{~d}, J=8.5 \mathrm{~Hz}, 2 \mathrm{H}), 7.00(\mathrm{~d}, J=8.5 \mathrm{~Hz}, 2 \mathrm{H}), 3.16(\mathrm{~s}, 3 \mathrm{H})$, 1.30 (s, 9H). ${ }^{13} \mathrm{C} \mathrm{NMR}\left\{{ }^{1} \mathrm{H}\right\}\left(101 \mathrm{MHz}, \mathrm{CDCl}_{3}\right) \delta$ 150.5, 138.8, $136.9,132.6,128.7,127.9,126.2,125.8,38.2,34.6,31.3 .{ }^{1} \mathrm{H} /{ }^{1} \mathrm{H}$ COSY NMR (400 MHz, $\left.\mathrm{CDCl}_{3}\right) \delta_{\mathrm{H}} / \delta_{\mathrm{H}} 7.59-7.57 / 7.46,7.30 / 7.00$, 3.16/3.16, $1.30 / 1.30 .{ }^{1} \mathrm{H} /{ }^{13} \mathrm{C}$ HSQC NMR $\left(400 \mathrm{MHz} \mathrm{CDCl}_{3}\right) \delta_{\mathrm{H}} /$ $\delta_{\mathrm{C}} 7.59-7.57 / 127.9,7.59-7.54 / 132.6,7.46 / 128.7,7.30 / 125.5,7.00 /$ 126.2, 3.16/38.2, 1.30/31.3. ${ }^{1} \mathrm{H} /{ }^{13} \mathrm{C}$ HMBC NMR (400 MHz, $\left.\mathrm{CDCl}_{3}\right) \delta_{\mathrm{H}} / \delta_{\mathrm{C}} 7.59-7.57 / 127.9,7.59-7.57 / 132.6,7.46 / 128.7,7.46 /$ 136.9, 7.30/125.8, 7.30/138.8, 7.00/126.2, 7.00/138.8, 7.00/150.5, $3.16 / 138.8,1.30 / 31.3,1.30 / 34.6,1.30 / 150.5$. GC/MS EI $\mathrm{m} / z 304$ $\left(\mathrm{M}^{+}+1,2\right), 303\left(\mathrm{M}^{+}, 14\right), 288(20), 162(45), 147(24), 146(25)$, 141 (11), 132 (21), 118 (12), 91 (21), 78 (11), 77 (100), 51 (42). HRMS (ESI-TOF ${ }^{+}$) m/z: $[\mathrm{M}+\mathrm{H}]^{+}$calcd for $\mathrm{C}_{17} \mathrm{H}_{22} \mathrm{NO}_{2} \mathrm{~S}$ : 304.1366; found 304.1383.

$N-\left(\left[1,1^{\prime}\right.\right.$-Biphenyl]-2-yl)-N-methylbenzenesulfonamide (1w). 1w was obtained from $1 \mathbf{w}-\mathbf{s}$ and was purified by column chromatography on silica gel eluting with pentane/EtOAc $(90: 10 \rightarrow 70: 30)$. A brown solid was isolated in $80 \%$ yield $(1.33 \mathrm{mmol}, 431.3 \mathrm{mg}) .{ }^{1} \mathrm{H}$ NMR $\left(400 \mathrm{MHz} \mathrm{CDCl}_{3}\right) \delta 7.60-7.53(\mathrm{~m}, 3 \mathrm{H}), 7.44-7.34(\mathrm{~m}, 9 \mathrm{H})$, $7.28-7.23(\mathrm{~m}, 1 \mathrm{H}), 7.01(\mathrm{~d}, J=7.8 \mathrm{~Hz}, 1 \mathrm{H}), 2.99(\mathrm{~s}, 3 \mathrm{H}) \cdot{ }^{13} \mathrm{C}$ $\mathrm{NMR}\left\{{ }^{1} \mathrm{H}\right\}\left(101 \mathrm{MHz}, \mathrm{CDCl}_{3}\right) \delta 142.4,139.3,139.1,138.8,132.5$, $131.5,129.1,128.8,128.4,128.1,128.1,127.8,127.7,127.2,39.2$. ${ }^{1} \mathrm{H} /{ }^{1} \mathrm{H}$ COSY NMR $\left(400 \mathrm{MHz}, \mathrm{CDCl}_{3}\right) \delta_{\mathrm{H}} / \delta_{\mathrm{H}} 7.60-7.54 / 7.46-$ 7.35, 7.46-7.35/7.29-7.25, 7.46-7.35/7.00, 7.29-7.25/7.00, 3.00/ 3.00. ${ }^{1} \mathrm{H} /{ }^{13} \mathrm{C}$ HSQC NMR (400 $\left.\mathrm{MHz}, \mathrm{CDCl}_{3}\right) \delta_{\mathrm{H}} / \delta_{\mathrm{C}} 7.60-7.54 /$ $127.8,7.60-7.54 / 132.5,7.46-7.35 / 127.2,7.46-7.35 / 128.1,7.46-$ $7.35 / 128.4,7.46-7.35 / 128.8,7.46-7.35 / 129.1,7.46-7.35 / 131.5$, 7.29-7.25/128.1, 7.00/127.7, 3.00/39.2. ${ }^{1} \mathrm{H} /{ }^{13} \mathrm{C}$ HMBC NMR $\left(400 \mathrm{MHz}, \mathrm{CDCl}_{3}\right) \quad \delta_{\mathrm{H}} / \delta_{\mathrm{C}} 7.60-7.54 / 127.8,7.60-7.54 / 132.5$, $7.60-7.54 / 127.8, \quad 7.46-7.35 / 127.2, \quad 7.45-7.35 / 127.7, \quad 7.46-7.35 /$ $127.8,7.46-7.35 / 128.1,7.46-7.35 / 128.8,7.46-7.35 / 129.1,7.46-$ $7.35 / 138.8,7.46-7.35 / 139.3,7.46-7.35 / 142.4,7.29-7.25 / 131.5$, 7.29-7.25/139.1, 7.00/128.4, 7.00/142.4, 3.00/139.1. GC/MS EI 
Table 6. Photoinduced Reduction of ArX with HE Anion ${ }^{a}$

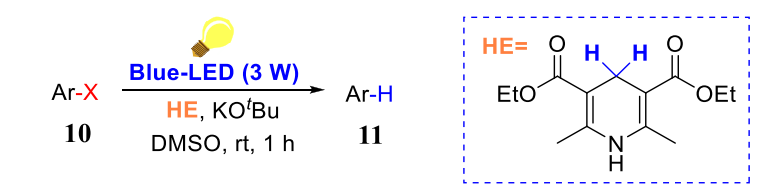

(1)

${ }^{a_{\text {The }}}$ photostimulated reaction $(1 \mathrm{~h})$ was carried out under $\mathrm{N}_{2}$ atmosphere using 10 ( 1 equiv, $0.1 \mathrm{mmol}$ ), $\mathrm{HE}$ (2 equiv), and $\mathrm{KO}^{t} \mathrm{Bu}$ (2.2 equiv) in DMSO $(1 \mathrm{~mL})$ using $3 \mathrm{~W}$ blue LED, at $\mathrm{rt}$ in a sealed tube. ${ }^{b}$ Yields were quantified by GC using the internal standard method.

$m / z 323\left(\mathrm{M}^{+}, 1\right), 182$ (66), 181 (26), 180 (28), 167 (85), 166 (14), 152 (15), 115 (11), 77 (100), 51 (54), 50 (11). HRMS (ESI-TOF ${ }^{+}$) $m / z:[\mathrm{M}+\mathrm{H}]^{+}$calcd for $\mathrm{C}_{19} \mathrm{H}_{18} \mathrm{NO}_{2} \mathrm{~S}$ 324.1053; found 324.1077.

$N$-Methyl-N-(4-(trifluoromethoxy)phenyl)benzenesulfonamide (1y). 1y was obtained from $\mathbf{1 y}-\mathbf{s}$ and was purified by column chromatography on silica gel eluting with hexane/EtOAc (95:5 $\rightarrow$ $80: 20)$. A brown oil was isolated in $70 \%$ yield $(0.7 \mathrm{mmol}, 232 \mathrm{mg})$.
${ }^{1} \mathrm{H}$ NMR (400 MHz, $\left.\mathrm{CDCl}_{3}\right) \delta 7.61-7.45(\mathrm{~m}, 5 \mathrm{H}), 7.16-7.10(\mathrm{~m}$, $4 \mathrm{H}), 3.16(\mathrm{~s}, 3 \mathrm{H}) .{ }^{13} \mathrm{C} \mathrm{NMR}\left\{{ }^{1} \mathrm{H}\right\}\left(101 \mathrm{MHz}, \mathrm{CDCl}_{3}\right) \delta$ 147.9, 140.0, 136.2, 133.0, 128.9, 128.0, 127.8, 121.3, 38.1. ${ }^{1} \mathrm{H} /{ }^{1} \mathrm{H}$ COSY NMR $\left(400 \mathrm{MHz}, \mathrm{CDCl}_{3}\right) \delta_{\mathrm{H}} / \delta_{\mathrm{H}} 7.61-7.45 / 7.61-7.45,7.16-7.10 /$ 7.16-7.10, 3.16/3.16. ${ }^{1} \mathrm{H} /{ }^{13} \mathrm{C}$ HSQC NMR $\left(400 \mathrm{MHz}, \mathrm{CDCl}_{3}\right) \delta_{\mathrm{H}} /$ $\delta_{\mathrm{C}} 7.61-7.45 / 127.8,7.61-7.45 / 128.9,7.61-7.45 / 133.0,7.16-7.10 /$ 121.3, 7.16-7.10/128.0, 3.16/38.1. ${ }^{1} \mathrm{H} /{ }^{13} \mathrm{C}$ HMBC NMR (400 $\left.\mathrm{MHz}, \quad \mathrm{CDCl}_{3}\right) \quad \delta_{\mathrm{H}} / \delta_{\mathrm{C}} 7.61-7.45 / 127.8,7.61-7.45 / 128.9,7.61-$ $7.45 / 133.0, \quad 7.61-7.45 / 136.1,7.16-7.10 / 121.3,7.16-7.10 / 128.0$, 7.16-7.10/139.9, 7.16-7.10/147.9, 3.16/139.9. ${ }^{19} \mathrm{~F}$ NMR (377 $\left.\mathrm{MHz}, \mathrm{CDCl}_{3}\right) \delta$-58.0. GC/MS EI $m / z 332\left(\mathrm{M}^{+}+1,2\right), 331$ $\left(\mathrm{M}^{+}, 15\right), 190$ (81), $162(11), 95$ (20), 92 (11), 78 (11), 77 (100), 69 (16), 66 (12), 65 (11), 51 (61), 50 (16). HRMS (ESI-TOF $\left.{ }^{+}\right) \mathrm{m} /$ $z:[\mathrm{M}+\mathrm{H}]^{+}$calcd for $\mathrm{C}_{14} \mathrm{H}_{13} \mathrm{~F}_{3} \mathrm{NO}_{3} \mathrm{~S}$ 332.0563; found 332.0572 .

One-Pot Synthesis of N-Methyl-N-arylsulfonamides. 1s, 1t, $1 \mathbf{x}$, $\mathbf{1 z}$, and $\mathbf{1 a b}$ were prepared by a one-pot synthesis starting from the corresponding anilines $(2 \mathrm{mmol})$. First, the sulfonylation reaction was carried out according to methods $\mathrm{A}-\mathrm{E}$, and second, without purification, methylation reaction proceeded.

$N$-(4-Fluorophenyl)- $N$-methylbenzenesulfonamide (1z). $1 \mathrm{z}$ was obtained from 4-fluoroaniline according to methods $\mathrm{E}$ and methylation reaction and was purified by column chromatography on silica gel eluting with hexane/EtOAc $(95: 5 \rightarrow 80: 20)$. A brown oil was isolated in $79 \%$ global yield $(1.57 \mathrm{mmol}, 416 \mathrm{mg}) .{ }^{1} \mathrm{H}$ NMR $\left(400 \mathrm{MHz} \mathrm{CDCl}_{3}\right) \delta 7.61-7.44(\mathrm{~m}, 5 \mathrm{H}) .7 .06-6.95(\mathrm{~m}, 4 \mathrm{H}), 3.16$ (s, 3H). ${ }^{13} \mathrm{C} \mathrm{NMR}\left\{{ }^{1} \mathrm{H}\right\}\left(101 \mathrm{MHz}, \mathrm{CDCl}_{3}\right) \delta 161.5(\mathrm{~d}, J=248 \mathrm{~Hz}$, 1C), 137.4 (d, $J=3,1 \mathrm{C}), 136.3,132.8,128.8,128.5(\mathrm{~d}, J=9 \mathrm{~Hz}$, 2C), 127.8, 115.7 (d, $J=23 \mathrm{~Hz}, 2 \mathrm{C}), 38.3 .{ }^{1} \mathrm{H} /{ }^{1} \mathrm{H}$ COSY NMR $(400$ $\left.\mathrm{MHz}, \mathrm{CDCl}_{3}\right) \delta_{\mathrm{H}} / \delta_{\mathrm{H}} 7.61-7.44 / 7.61-7.44,7.06-6.95 / 7.06-6.95$, 3.16/3.16. ${ }^{1} \mathrm{H} /{ }^{13} \mathrm{C}$ HSQC NMR $\left(400 \mathrm{MHz}, \mathrm{CDCl}_{3}\right) \delta_{\mathrm{H}} / \delta_{\mathrm{C}} 7.61-$ 7.44/127.8, 7.61-7.44/128.8, 7.61-7.44/132.8, 7.06-6.95/115.7, 7.06-6.95/128.5, 3.16/38.3. ${ }^{1} \mathrm{H} /{ }^{13} \mathrm{C}$ HMBC NMR (400 MHz, $\left.\mathrm{CDCl}_{3}\right) \delta_{\mathrm{H}} / \delta_{\mathrm{C}} 7.61-7.44 / 127.8,7.61-7.44 / 128.8,7.61-7.44 / 132.8$, $7.61-7.44 / 136.3,7.06-6.95 / 115.7,7.06-6.95 / 128.5,7.06-6.95 /$ 137.4, 7.06-6.95/161.5, 3.16/137.4. ${ }^{19} \mathrm{~F}$ NMR (377 $\mathrm{MHz}, \mathrm{CDCl}_{3}$ ) $\delta$-113.8. GC/MS EI $m / z 266\left(\mathrm{M}^{+}+1,2\right), 265\left(\mathrm{M}^{+}, 17\right), 124$ (100), 122 (14), 97 (26), 96 (29), 95 (41), 77 (80), 75 (21), 57 (13), 51 (51), 50 (15). HRMS (ESI-TOF $\left.{ }^{+}\right) \mathrm{m} / z:[\mathrm{M}+\mathrm{H}]^{+}$calcd for $\mathrm{C}_{13} \mathrm{H}_{13} \mathrm{FNO}_{2} \mathrm{~S}$ 266.0646; found 266.0654 .

$\mathrm{N}$-(3-Acetylphenyl)-N-methylbenzenesulfonamide (1ab). 1ab was obtained from 1-(3-amino phenyl)ethan-1-one according to method B and methylation reaction and was purified by column chromatography on silica gel eluting with hexane/EtOAc (100:0 $\rightarrow$ $75: 25)$. An orange oil was isolated in $65 \%$ global yield $(1.3 \mathrm{mmol}$, $373.4 \mathrm{mg}) .{ }^{1} \mathrm{H}$ NMR $\left(400 \mathrm{MHz}, \mathrm{CDCl}_{3}\right) \delta 7.87-7.85(\mathrm{~m}, 1 \mathrm{H})$, 7.62-7.37 (m, 8H), $3.20(\mathrm{~s}, 3 \mathrm{H}), 2.56(\mathrm{~s}, 3 \mathrm{H}) .{ }^{13} \mathrm{C} \mathrm{NMR}\left\{{ }^{1} \mathrm{H}\right\}(101$ $\left.\mathrm{MHz}, \mathrm{CDCl}_{3}\right) \delta 197.1,142.0,137.7,136.0,133.0,131.4,129.1$, 128.8, 127.7, 127.1, 125.7, 37.9, 26.6. ${ }^{1} \mathrm{H} /{ }^{1} \mathrm{H}$ COSY NMR (400 $\left.\mathrm{MHz}, \mathrm{CDCl}_{3}\right) \delta_{\mathrm{H}} / \delta_{\mathrm{H}} 7.87-7.85 / 7.62-7.37,3.20 / 3.20,2.56 / 2.56$. ${ }^{1} \mathrm{H} /{ }^{13} \mathrm{C}$ HSQC NMR $\left(400 \mathrm{MHz}, \mathrm{CDCl}_{3}\right) \delta_{\mathrm{H}} / \delta_{\mathrm{C}} 7.87-7.85 / 121.1$, $7.62-7.37 / 125.7,7.62-7.37 / 133.0,7.62-7.37 / 127.7,7.62-7.37 /$ 129.1, 7.62-7.37/128.8, 7.62-7.37/131.4. ${ }^{1} \mathrm{H} /{ }^{13} \mathrm{C}$ HMBC NMR $\left(400 \mathrm{MHz}, \mathrm{CDCl}_{3}\right) \quad \delta_{\mathrm{H}} / \delta_{\mathrm{C}} 7.87-7.85 / 125.7,7.87-7.85 / 134.4$, $7.87-7.85 / 197.1, \quad 7.62-7.37 / 127.1,7.62-7.37 / 127.7,7.62-7.37 /$ $128.8,7.62-7.37 / 131.4,7.62-7.37 / 133.0,7.62-7.37 / 136.0,7.62-$ 7.37/137.7, 7.62-7.37/142.0, 7.62-7.37/197.1, 3.20/142.0, 2.56/ 197.1. HRMS (ESI-TOF ${ }^{+}$) $m / z:[\mathrm{M}+\mathrm{H}]^{+}$calcd for $\mathrm{C}_{15} \mathrm{H}_{16} \mathrm{NO}_{3} \mathrm{~S}$ 290.0845; found 290.0860 .

Desulfonylation Reactions in Dark Conditions. The desulfonylation reaction was carried out in a Schlenk tube equipped with an inert $\mathrm{N}_{2}$ inlet and magnetically stirred at rt. In the Schlenk tube, DMSO $(1 \mathrm{~mL})$ was dried and deoxygenated; then, the corresponding sulfonamide ( 1 equiv, $0.1 \mathrm{mmol}$ ) and $\mathrm{KO}^{t} \mathrm{Bu}$ (3 equiv, $0.3 \mathrm{mmol}$ ) were added and the mixture was protected from light with aluminum foil. After the reaction was finished, it was quenched with $\mathrm{NH}_{4} \mathrm{NO}_{3}$ or $\mathrm{NH}_{4} \mathrm{Cl}$ and water in excess and the residue was extracted with EtOAc $(3 \times 30 \mathrm{~mL})$, and the organic layers extracted were combined, washed with water, dried with anhydrous $\mathrm{Na}_{2} \mathrm{SO}_{4}$, and concentrated under reduced pressure to leave the crude products. 
Yields were quantified by GC employing the internal method using biphenyl as the internal standard.

Photodesulfonylation Reactions under Visible Light Irradiation. The photodesulfonylation reactions were carried out in a vial at $\mathrm{rt}$ and under $\mathrm{N}_{2}$ atmosphere and irradiated with blue LED $(3 \mathrm{~W})$ using 1 equiv $(0.1 \mathrm{mmol})$ of sulfonamide, 2.2 equiv of $\mathrm{KO}^{t} \mathrm{Bu}(0.22$ $\mathrm{mmol})$, and 2 equiv of Hantzsch ester $(0.2 \mathrm{mmol})$ in DMSO $(1 \mathrm{~mL}$ of previously dried and deoxygenated). After the reaction was finished, it was quenched with $\mathrm{NH}_{4} \mathrm{NO}_{3}$ or $\mathrm{NH}_{4} \mathrm{Cl}$ and water in excess and the residue was extracted with EtOAc $(3 \times 30 \mathrm{~mL})$, and the organic layers extracted were combined, washed with water, dried with anhydrous $\mathrm{Na}_{2} \mathrm{SO}_{4}$, and concentrated under reduced pressure to leave the crude products. Yields were quantified by GC using the internal method employing $9 \mathrm{H}$-carbazole as the internal standard.

Characterization Data of Desulfonylation Products (2). $1 \mathrm{H}$ Indole (2a), $1 H$-pyrrolo[2,3-b]pyridine (2b), $1 H$-benzo[d][1,2,3]triazole (2c), $1 \mathrm{H}$-pyrrole $(\mathbf{2 d}), 9 \mathrm{H}$-carbazole $(\mathbf{2 e})$, diphenylamine (2i), aniline (2k), 4-methoxyphenol (2n), 4-hydroxybenzonitrile (2o), 2-iodophenol (2p), and 1-benzyl-1H-indole (2q) were identified by comparing with authentic samples (GC/flame ionization detector (FID) and GC/MS).

$1 \mathrm{H}$-Indole (2a). The title compound was purified by column chromatography on silica gel eluting with hexane/EtOAc (100:0 $\rightarrow$ $80: 20)$ in $91 \%$ yield $(0.091 \mathrm{mmol}, 10.6 \mathrm{mg})$ as a white solid. Starting from $0.5 \mathrm{mmol}$ of substrate, $88 \%$ isolated yield $(0.44 \mathrm{mmol}, 51.5 \mathrm{mg})$ was obtained. For large-scale reaction, the isolated yield was $86 \%$ $(3.6 \mathrm{mmol}, 423 \mathrm{mg}$ ) starting from $1.080 \mathrm{~g}$ of substrate.

$1 \mathrm{H}$-Pyrrolo[2,3-b]pyridine (2b). The title compound was purified by column chromatography on silica gel eluting with hexane/EtOAc $(100: 0 \rightarrow 80: 20)$ in $87 \%$ yield $(0.087 \mathrm{mmol}, 10.2 \mathrm{mg})$ as a white solid.

1 H-Benzo[d][1,2,3]triazole (2c). The title compound was purified by column chromatography on silica gel eluting with hexane/EtOAc $(100: 0 \rightarrow 80: 20)$ in $67 \%$ yield $(0.067 \mathrm{mmol}, 8.0 \mathrm{mg})$ as a white solid.

$1 \mathrm{H}$-Pyrrole (2d). The title compound was purified by column chromatography on silica gel eluting with hexane/EtOAc (100:0 $\rightarrow$ $80: 20)$ in $99 \%$ yield $(0.099 \mathrm{mmol}, 6.6 \mathrm{mg}$ ) as a colorless oil.

$9 \mathrm{H}$-Carbazole (2e). The title compound was purified by column chromatography on silica gel eluting with hexane/EtOAc (100:0 $\rightarrow$ $80: 20)$ in $47 \%$ yield $(0.047 \mathrm{mmol}, 7.8 \mathrm{mg}$ ) as a white solid.

Diphenylamine (2i). The title compound was obtained in $72 \%$ yield $(0.072 \mathrm{mmol}, 12.2 \mathrm{mg})$ as a brown solid.

4-Methoxyphenol (2n). The title compound was purified by column chromatography on silica gel eluting with hexane/EtOAc (50:50) in $75 \%$ yield $(0.075 \mathrm{mmol}, 9.3 \mathrm{mg})$ as a light-pink solid.

4-Hydroxybenzonitrile (2o). The title compound was purified by column chromatography on silica gel eluting with hexane/EtOAc (50:50) in $90 \%$ yield $(0.09 \mathrm{mmol}, 10.7 \mathrm{mg})$ as a white solid.

2-lodophenol (2p). The title compound was purified by column chromatography on silica gel eluting with hexane/EtOAc (50:50) in $93 \%$ yield $(0.093 \mathrm{mmol}, 20.5 \mathrm{mg})$ as a gray solid.

1-Benzyl-1H-indole (2q). The title compound was purified by column chromatography on silica gel eluting with hexane/EtOAc (80:20) in $98 \%$ yield $(0.098 \mathrm{mmol}, 20.3 \mathrm{mg})$ as a colorless oil.

$\mathrm{N}$-Methylaniline (2l). ${ }^{104}$ The title compound was purified by column chromatography on silica gel eluting with hexane/EtOAc $(90: 10 \rightarrow 50: 50)$ in $95 \%$ yield $(0.095 \mathrm{mmol}, 10 \mathrm{mg})$ as a brown oil. ${ }^{1} \mathrm{H}$ NMR (400 MHz, $\left.\mathrm{CDCl}_{3}\right) \delta 7.20-7.16(\mathrm{~m}, 2 \mathrm{H}), 6.70(\mathrm{t}, J=7.3$ $\mathrm{Hz}, 1 \mathrm{H}), 6.59(\mathrm{~d}, J=7.7 \mathrm{~Hz}, 2 \mathrm{H}), 3.64(\mathrm{~s} \mathrm{br}, 1 \mathrm{H}), 2.80(\mathrm{~s}, 3 \mathrm{H}) .{ }^{13} \mathrm{C}$ $\mathrm{NMR}\left\{{ }^{1} \mathrm{H}\right\}\left(101 \mathrm{MHz}, \mathrm{CDCl}_{3}\right) \delta 149.3,129.1,117.2,112.3,30.6$. GC/MS EI $m / z 108\left(8, \mathrm{M}^{+}+1\right), 107\left(81 \mathrm{M}^{+}\right), 106(100), 79$ (33), 78 (14), 77 (39), 65 (14), 51 (23), 50 (8).

$\mathrm{N}$-(4-Hydroxyphenyl)-N,4-dimethylbenzenesulfonamide (2m). ${ }^{105}$ The title compound was purified by column chromatography on silica gel eluting with hexane/EtOAc $(90: 10 \rightarrow 50: 50)$. A brown oil was isolated in $44 \%$ yield $(0.014 \mathrm{mmol}, 4 \mathrm{mg}) .{ }^{1} \mathrm{H}$ NMR $\left(400 \mathrm{MHz}, \mathrm{CDCl}_{3}\right) \delta 7.45(\mathrm{~d}, J=8.0 \mathrm{~Hz}, 2 \mathrm{H}), 7.26-7.24(\mathrm{~m}, 2 \mathrm{H})$, $6.93(\mathrm{~d}, J=8.6 \mathrm{~Hz}, 2 \mathrm{H}), 6.73(\mathrm{~d}, J=8.6 \mathrm{~Hz}, 2 \mathrm{H}), 5.19(\mathrm{~s} \mathrm{br}, 1 \mathrm{H})$, $3.12(\mathrm{~s}, 3 \mathrm{H}), 2.42(\mathrm{~s}, 3 \mathrm{H}),{ }^{13} \mathrm{C} \operatorname{NMR}\left\{{ }^{1} \mathrm{H}\right\}\left(101 \mathrm{MHz}, \mathrm{CDCl}_{3}\right) \delta$
$154.9,143.5,134.4,133.6,129.3,128.4,128.0,115.6,38.4,21.5 . \mathrm{GC} /$ MS EI $m / z 279\left(\mathrm{M}^{+}+2,1\right), 278\left(\mathrm{M}^{+}+1,2\right), 277\left(\mathrm{M}^{+}, 10\right), 123$ (7), 122 (100), 94 (19), 91 (11), 65 (18).

4-Methoxy-N-methylaniline (2s). ${ }^{106}$ The title compound was purified by column chromatography on silica gel eluting with hexane/EtOAc $(100: 0 \rightarrow 70: 30)$. A light yellow oil was isolated in $80 \%$ yield (0.08 mmol, $9.8 \mathrm{mg}) .{ }^{1} \mathrm{H} \mathrm{NMR}\left(400 \mathrm{MHz}, \mathrm{CDCl}_{3}\right) \delta 7.25$ (s, $1 \mathrm{H}), 6.82-6.78(\mathrm{~m}, 2 \mathrm{H}), 6.61-6.57(\mathrm{~m}, 2 \mathrm{H}), 3.75(\mathrm{~s}, 3 \mathrm{H}), 2.80$ $(\mathrm{s}, 3 \mathrm{H}) .{ }^{13} \mathrm{C} \mathrm{NMR}\left\{{ }^{1} \mathrm{H}\right\}\left(101 \mathrm{MHz}, \mathrm{CDCl}_{3}\right) \delta 152.1,143.7,114.9$, 113.6, 55.8, 31.6. GC/MS EI $m / z 138\left(\mathrm{M}^{+}+1,4\right), 137\left(\mathrm{M}^{+}, 61\right)$, 122 (100), 94 (60), 77 (13), 67 (13), 66 (12), 65 (35), 63 (23), 53 (18), 52 (26), 51 (15), 50 (8).

4-Methyl-N-methylaniline (2t). ${ }^{104}$ The title compound was obtained in $98 \%$ yield $(0.098 \mathrm{mmol}, 11.9 \mathrm{mg}) .{ }^{1} \mathrm{H}$ NMR (400 $\left.\mathrm{MHz}, \mathrm{CDCl}_{3}\right) \delta 6.99(\mathrm{~d}, J=8.5 \mathrm{~Hz}, 2 \mathrm{H}), 6.54(\mathrm{~d}, J=8.4 \mathrm{~Hz}, 2 \mathrm{H})$, 3.51 (s br, $1 \mathrm{H}), 2.80$ (s, 3H), $2.24(\mathrm{~s}, 3 \mathrm{H}) .{ }^{13} \mathrm{C} \operatorname{NMR}\left\{{ }^{1} \mathrm{H}\right\}(101$ $\left.\mathrm{MHz}, \mathrm{CDCl}_{3}\right) \delta 147.2,129.7,126.4,112.6,31.1,20.3$. GC/MS EI $m / z 122\left(\mathrm{M}^{+}+1,7\right), 121\left(\mathrm{M}^{+}, 93\right), 120(100), 106(13), 91(41)$, 89 (10), 79 (12), 78 (15), 77 (26), 65 (25), 63 (16), 60 (12), 53 (11), 52 (18), 51 (26), 50 (16).

4-Cyano-N-methylaniline $(\mathbf{2 u}) .^{107}$ The title compound was purified by column chromatography on silica gel eluting with hexane/EtOAc $(80: 20 \rightarrow 50: 50)$ as a colorless oil and isolated in $50 \%$ yield $(0.05 \mathrm{mmol}, 6.6 \mathrm{mg}) .{ }^{1} \mathrm{H} \mathrm{NMR}\left(400 \mathrm{MHz}, \mathrm{CDCl}_{3}\right) \delta 7.43$ $(\mathrm{d}, J=8.6 \mathrm{~Hz}, 2 \mathrm{H}), 6.55(\mathrm{~d}, J=8.6 \mathrm{~Hz}, 2 \mathrm{H}), 4.25(\mathrm{~s} \mathrm{br}, 1 \mathrm{H}), 2.88$ $(\mathrm{s}, 3 \mathrm{H}) .{ }^{13} \mathrm{C} \mathrm{NMR}\left\{{ }^{1} \mathrm{H}\right\}\left(101 \mathrm{MHz}, \mathrm{CDCl}_{3}\right) \delta 152.2,133.7,120.4$, 111.8, 30.0. GC/MS EI $m / z 133\left(\mathrm{M}^{+}+1,7\right), 132\left(\mathrm{M}^{+}, 74\right), 131$ (100), 104 (22), 102 (14), 77 (17), 76 (13), 75 (14), 66 (12), 64 (11), 63 (13), 51 (15), 50 (11).

4-(tert-Butyl)-N-methylaniline (2v). ${ }^{106}$ The title compound was purified by column chromatography on silica gel eluting with hexane/EtOAc $(95: 5 \rightarrow 80: 20)$ as a colorless oil and isolated in $80 \%$ yield (0.08 mmol, $13.0 \mathrm{mg}) .{ }^{1} \mathrm{H} \mathrm{NMR}\left(400 \mathrm{MHz}, \mathrm{CDCl}_{3}\right) \delta 7.22$ (d, $J=8.5 \mathrm{~Hz}, 2 \mathrm{H}), 6.59(\mathrm{~d}, J=8.5 \mathrm{~Hz}, 2 \mathrm{H}), 3.57(\mathrm{~s} \mathrm{br}, 1 \mathrm{H}), 2.82(\mathrm{~s}$, $3 \mathrm{H}), 1.28$ (s, 9H). ${ }^{13} \mathrm{C} \operatorname{NMR}\left\{{ }^{1} \mathrm{H}\right\}\left(101 \mathrm{MHz}, \mathrm{CDCl}_{3}\right) \delta 147.0$, 140.1, 126.0, 112.2, 33.8, 31.6, 31.0. GC/MS EI $m / z 164\left(\mathrm{M}^{+}+1\right.$, 3), $163\left(\mathrm{M}^{+}, 28\right), 149$ (11), 148 (100), 133 (16), 120 (21), 108 (12), 107 (13), 91 (13), 77 (16), 65 (12), 50 (3).

N-Methyl-[1, $1^{\prime}$-biphenyl]-2-amine $(2 w){ }^{104}$ The title compound was purified by column chromatography on silica gel eluting with hexane/EtOAc $(100: 0 \rightarrow 90: 10)$ as a light yellow oil and isolated in $86 \%$ yield $(0.086 \mathrm{mmol}, 15.7 \mathrm{mg}) .{ }^{1} \mathrm{H}$ NMR $\left(400 \mathrm{MHz}, \mathrm{CDCl}_{3}\right) \delta$ 7.44-7.40 (m, 4H), 7.35-7.32 (m, 2H), $7.08(\mathrm{dd}, J=7.4,1.2 \mathrm{~Hz}$, $1 \mathrm{H}), 6.76(\mathrm{t}, J=7.4 \mathrm{~Hz}, 1 \mathrm{H}), 6.68(\mathrm{~d}, J=8.1 \mathrm{~Hz}, 1 \mathrm{H}), 4.09(\mathrm{~s} \mathrm{br}$, $1 \mathrm{H}), 2.78(\mathrm{~s}, 3 \mathrm{H})$.

4-(Trifluoromethoxy)-N-methylaniline $(2 y) .^{107}$ The title compound was purified by column chromatography on silica gel eluting with hexane/EtOAc $(90: 10 \rightarrow 70: 30)$ as a colorless oil and isolated in $58 \%$ yield $(0.058 \mathrm{mmol}, 11.1 \mathrm{mg}) .{ }^{1} \mathrm{H} \mathrm{NMR}\left(400 \mathrm{MHz}, \mathrm{CDCl}_{3}\right) \delta$ $7.03(\mathrm{~d}, J=8.8 \mathrm{~Hz}, 2 \mathrm{H}), 6.54-6.52(\mathrm{~m}, 2 \mathrm{H}), 3.72(\mathrm{~s} \mathrm{br}, 1 \mathrm{H}), 2.8(\mathrm{~s}$, $3 \mathrm{H}) .{ }^{13} \mathrm{C} \mathrm{NMR}\left\{{ }^{1} \mathrm{H}\right\}\left(101 \mathrm{MHz}, \mathrm{CDCl}_{3}\right) \delta 148.1,140.4,122.3,120.8$ $(\mathrm{q}, J=255 \mathrm{~Hz}, 1 \mathrm{C}), 112.5,30.7$. GC/MS EI $m / z 192\left(\mathrm{M}^{+}+1,6\right)$, $191\left(\mathrm{M}^{+}, 60\right), 190$ (16), 123 (10), 122 (100), 106 (11), 95 (16), 94 (54), 79 (12), 78 (12), 77 (32), 75 (11), 69 (36), 67 (15), 66 (15), 65 (38), 64 (16), 63 (21), 53 (17), 52 (23), 51 (14).

4-Fluoro-N-methylaniline (2z). ${ }^{107}$ The title compound was obtained in $85 \%$ yield $(0.085 \mathrm{mmol}, 10.6 \mathrm{mg})$ as a colorless oil. ${ }^{1} \mathrm{H}$ NMR (400 MHz, $\left.\mathrm{CDCl}_{3}\right) \delta 6.93-6.86(\mathrm{~m}, 2 \mathrm{H}), 6.55-6.51(\mathrm{~m}$, $2 \mathrm{H}), 3.32$ (s br, $1 \mathrm{H}), 2.80(\mathrm{~s}, 3 \mathrm{H}) .{ }^{13} \mathrm{C} \operatorname{NMR}\left\{{ }^{1} \mathrm{H}\right\}(101 \mathrm{MHz}$, $\left.\mathrm{CDCl}_{3}\right) \delta 155.8(\mathrm{~d}, J=234,1 \mathrm{C}), 145.7,115.6(\mathrm{~d}, J=22 \mathrm{~Hz}, 2 \mathrm{C})$, $113.1(\mathrm{~d}, J=7 \mathrm{~Hz}, 2 \mathrm{C}), 31.3$. GC/MS EI $m / z 126\left(\mathrm{M}^{+}+1,7\right), 125$ $\left(\mathrm{M}^{+}, 89\right), 124$ (100), 97 (32), 96 (20), 95 (20), 83 (23), 77 (17), 75 (18), 62 (15), 57 (12).

1-(3-(Methylamino)phenyl)ethan-1-one (2ab). ${ }^{108}$ The title compound was purified by column chromatography on silica gel eluting with hexane/EtOAc $(90: 10 \rightarrow 70: 30)$ as a white solid in $85 \%$ yield (0.085 mmol, $12.7 \mathrm{mg}) .{ }^{1} \mathrm{H}$ NMR $\left(400 \mathrm{MHz}, \mathrm{CDCl}_{3}\right) \delta 7.28-7.26$ $(\mathrm{m}, 2 \mathrm{H}), 7.20-7.18(\mathrm{~m}, 1 \mathrm{H}), 6-81-6.78(\mathrm{~m}, 1 \mathrm{H}), 3.90(\mathrm{~s} \mathrm{br}, 1 \mathrm{H})$, $2.88(\mathrm{~s}, 3 \mathrm{H}), 2.58(\mathrm{~s}, 3 \mathrm{H})$. 
Photoinduced Reduction of Aryl Halides in Presence of HE. Photostimulated reduction was carried out under $\mathrm{N}_{2}$ atmosphere using 1 equiv $(0.1 \mathrm{mmol})$ of the corresponding aryl halide, 2 equiv of $\mathrm{HE}$ and $\mathrm{KO}^{t} \mathrm{Bu}(2.2$ equiv) in DMSO $(1 \mathrm{~mL})$, and irradiating with 3 $\mathrm{W}$ blue LED at rt. DMSO was previously dried and deoxygenated. After the reaction was finished, it was quenched with $\mathrm{NH}_{4} \mathrm{NO}_{3}$ or $\mathrm{NH}_{4} \mathrm{Cl}$ and water in excess. The residue was extracted with EtOAc $(3 \times 30 \mathrm{~mL})$, and the organic layers were combined, washed with water, dried with anhydrous $\mathrm{Na}_{2} \mathrm{SO}_{4}$, and concentrated under reduced pressure to leave the crude products. Yields were quantified by GC using the internal method using $9 \mathrm{H}$-carbazole as the internal standard. Naphthalene (11a), anthracene (11d), phenanthrene (11e), biphenyl (11f), pyridine (11g), and cyanobenzene (11i) were identified by comparing with authentic samples (GC/FID and GC/MS).

Naphthalene (11a). The title compound was obtained in $81 \%$ yield $(0.081 \mathrm{mmol}, 10.4 \mathrm{mg})$ as a white solid.

Anthracene (11d). The title compound was obtained in $89 \%$ yield (0.089 mmol, $15.9 \mathrm{mg})$ as a white solid.

Phenanthrene (11e). The title compound was obtained in $93 \%$ yield $(0.093 \mathrm{mmol}, 16.5 \mathrm{mg})$ as white solid.

Biphenyl (11f). The title compound was obtained in $76 \%$ yield (0.076 mmol, $11.6 \mathrm{mg}$ ) as a white solid.

Pyridine (11g). The title compound was obtained in 59\% yield $(0.059 \mathrm{mmol}, 4.67 \mathrm{mg})$ as a colorless oil.

Cyanobenzene (11i). The title compound was obtained in $45 \%$ yield $(0.045 \mathrm{mmol}, 4.6 \mathrm{mg})$ as a colorless oil.

\section{ASSOCIATED CONTENT}

\section{(3) Supporting Information}

The Supporting Information is available free of charge at https://pubs.acs.org/doi/10.1021/acs.joc.0c01523.

Extra experimental details, UV-vis spectra, ${ }^{1} \mathrm{H}$ NMR and ${ }^{13} \mathrm{C}$ NMR $\left\{{ }^{1} \mathrm{H}\right\}$ spectra for substrates and products, emission spectrum for blue LEDs and HPIT $400 \mathrm{~W}$ lamps $(\lambda \geq 350 \mathrm{~nm}$, Figures S1 and S2); UV-vis spectra (Figures S3-S6); light sources (Table S1); sulfonylation (Table S2); and methylation of sulfonamides (Table S3) (PDF)

\section{AUTHOR INFORMATION}

\section{Corresponding Author}

María E. Budén - INFIQC, Facultad de Ciencias Químicas, Universidad Nacional de Córdoba, X5000HUA Córdoba,

Argentina; O orcid.org/0000-0002-2424-3299;

Email: eugebuden@unc.edu.ar

\section{Authors}

Micaela D. Heredia - INFIQC, Facultad de Ciencias Químicas, Universidad Nacional de Córdoba, X5000HUA Córdoba, Argentina

Walter D. Guerra - INFIQC, Facultad de Ciencias Químicas, Universidad Nacional de Córdoba, X5000HUA Córdoba, Argentina

Silvia M. Barolo - INFIQC, Facultad de Ciencias Químicas, Universidad Nacional de Córdoba, X5000HUA Córdoba, Argentina

Santiago J. Fornasier - INFIQC, Facultad de Ciencias Qúmicas, Universidad Nacional de Córdoba, X5000HUA Córdoba, Argentina

Roberto A. Rossi - INFIQC, Facultad de Ciencias Químicas, Universidad Nacional de Córdoba, X5000HUA Córdoba, Argentina; (1) orcid.org/0000-0001-8659-082X

Complete contact information is available at: https://pubs.acs.org/10.1021/acs.joc.0c01523

\section{Notes}

The authors declare no competing financial interest.

\section{ACKNOWLEDGMENTS}

This work was supported partly by Agencia Córdoba Ciencia, Consejo Nacional de Investigaciones Científicas y Técnicas (CONICET), Secretaría de Ciencia y Tecnología, Universidad Nacional de Córdoba (SECyT), and Agencia Nacional de Promoción Científica y Técnica (ANPCyT). M.D.H. gratefully acknowledge receipt of fellowship from CONICET.

\section{REFERENCES}

(1) Wuts, P. G. M.; Greene, T. W. Protection for the Amino Group. Greene's Protective Groups in Organic Synthesis; John Wiley \& Sons, Inc.: Hoboken, NJ, 2006; 696.

(2) Thomas, E. J. Protecting Groups. Philip J. Kocienski. Georg Thieme, Stuttgart, New York. Appl. Organomet. Chem. 2001, 15, $725-726$.

(3) Kan, T.; Fukuyama, T. Ns Strategies: A Highly Versatile Synthetic Method for Amines. Chem. Commun. 2004, 4, 353-359.

(4) Snyder, H. R.; Heckert, R. E. A Method for the Rapid Cleavage of Sulfonamides 1. J. Am. Chem. Soc. 1952, 74, 2006-2009.

(5) Weisblat, D. I.; Magerlein, B. J.; Myers, D. R. The Cleavage of Sulfonamides. J. Am. Chem. Soc. 1953, 75, 3630-3632.

(6) Wellner, E.; Sandin, H.; Pääkkönen, L. Synthesis of 6,6Difluorohomopiperazines via Microwave-Assisted Detosylation. Synthesis 2003, 2, 0223-0226.

(7) Searles, S.; Nukina, S. Cleavage and Rearrangement of Sulfonamides. Chem. Rev. 1959, 59, 1077-1103.

(8) Nolan, C.; Gunnlaugsson, T. Improved Synthesis of a $\mathrm{C}_{3^{-}}$ Symmetrical Pyridinophane. Tetrahedron Lett. 2008, 49, 1993-1996.

(9) Sakamoto, I.; Izumi, N.; Yamada, T.; Tsunoda, T. 2-(1,3Dioxan-2-il)ethylsulfonyl Group: A New Versatile Protecting and Activating Group for Amine Synthesis. Org. Lett. 2006, 8, 71-74.

(10) Javorskis, T.; Orentas, E. Chemoselective Deprotection of Sulfonamides Under Acidic Conditions: Scope, Sulfonyl Group Migration, and Synthetic Applications. J. Org. Chem. 2017, 82, 13423-13439.

(11) Oppolzer, W.; Bienayme, H.; Genevois-Borella, A. Enantioselective Synthesis of (+)-3-Isorauniticine via a Catalytic Tandem Palladium-Ene/carbonylation Reaction. J. Am. Chem. Soc. 1991, 113, 9660-9661.

(12) Kudav, D. P.; Samant, S. P.; Hosangadi, B. D. Perchloric AcidAcetic Acid: A Reagent System for Detosylation. Synth. Commun. 1987, 17, 1185-1187.

(13) Merrill, B. A.; LeGoff, E. A General Synthetic Route to 2,2':5',2"'-terpyrrole, 2,5-di(2-Pyrryl)thiophene, and Alkyl-Substituted Analogs. J. Org. Chem. 1990, 55, 2904-2908.

(14) Garg, N. K.; Sarpong, R.; Stoltz, B. M. The First Total Synthesis of Dragmacidin D. J. Am. Chem. Soc. 2002, 124, 1317913184.

(15) Liu, Y.; Shen, L.; Prashad, M.; Tibbatts, J.; Repič, O.; Blacklock, T. J. A Green N-Detosylation of Indoles and Related Heterocycles Using Phase Transfer Catalysis. Org. Process Res. Dev. 2008, 12, 778-780.

(16) Chaulet, C.; Croix, C.; Basset, J.; Pujol, M.; Viaud-Massuard, M.-C. Desulfonylation of Indoles and 7-Azaindoles Using Sodium tert-Butoxide. Synlett 2010, 10, 1481-1484.

(17) Haskins, C. M.; Knight, D. W. Efficient Indole N-Detosylation Using Thioglycolate. Tetrahedron Lett. 2004, 45, 599-601.

(18) Bajwa, J. S.; Chen, G.; Prasad, K.; Repič, O.; Blacklock, T. J. Deprotection of $\mathrm{N}$-Tosylated Indoles and Related Structures Using Cesium Carbonate. Tetrahedron Lett. 2006, 47, 6425-6427.

(19) Fleming, I.; Frackenpohl, J.; Ila, H. Cleavage of Sulfonamides with Phenyldimethylsilyllithium. J. Chem. Soc., Perkin Trans. 1 1998, 7, 1229-1236. 
(20) Gold, E. H.; Babad, E. Reductive Cleavage of Sulfonamides with Sodium Bis(2-Methoxyethoxy)aluminum Hydride. J. Org. Chem. 1972, 37, 2208-2210.

(21) Itoh, T.; Yokoya, M.; Miyauchi, K.; Nagata, K.; Ohsawa, A. Proline-Catalyzed Asymmetric Addition Reaction of 9-Tosyl-3,4Dihydro- $\beta$-Carboline with Ketones. Org. Lett. 2003, 5, 4301-4304.

(22) Mendiola, J.; Baeza, A.; Alvarez-Builla, J.; Vaquero, J. J. Reaction of Bromomethylazoles and Tosylmethyl Isocyanide. A Novel Heterocyclization Method for the Synthesis of the Core of Marine Alkaloids Variolins and Related Azolopyrimidines. J. Org. Chem. 2004, 69, 4974-4983.

(23) Ankner, T.; Hilmersson, G. Instantaneous Deprotection of Tosylamides and Esters with $\mathrm{SmI}_{2} /$ Amine/Water. Org. Lett. 2009, 11, 503-506.

(24) Vedejs, E.; Lin, S. Deprotection of Arenesulfonamides with Samarium Iodide. J. Org. Chem. 1994, 59, 1602-1603.

(25) Knowles, H.; Parsons, A.; Pettifer, R. Desulfonylation of Amides Using Samarium Iodide. Synlett 1997, 1997, 271-272.

(26) Jensen, K. L.; Franke, P. T.; Nielsen, L. T.; Daasbjerg, K.; Jørgensen, K. A. Anodic Oxidation and Organocatalysis: Direct Regio- and Stereoselective Access to Meta-Substituted Anilines by $\alpha$ Arylation of Aldehydes. Angew. Chem., Int. Ed. 2010, 49, 129-133.

(27) Blay, G.; Cardona, L.; Climent, E.; Pedro, J. R. Highly Enantioselective Zinc/binol-Catalyzed Alkynylation of $\mathrm{N}$-Sulfonyl Aldimines. Angew. Chem., Int. Ed. 2008, 47, 5593-5596.

(28) Kuriyama, M.; Soeta, T.; Hao, X.; Chen, Q.; Tomioka, K. NBoc-L-Valine-Connected Amidomonophosphane Rhodium(I) Catalyst for Asymmetric Arylation of $N$ - Tosylarylimines with Arylboroxines. J. Am. Chem. Soc. 2004, 126, 8128-8129.

(29) Nyasse, B.; Grehn, L.; Ragnarsson, U. Mild, Efficient Cleavage of Arenesulfonamides by Magnesium Reduction. Chem. Commun. 1997, 11, 1017-1018.

(30) Das, I.; Pathak, T. Desulfonylation with $\mathrm{Mg}-\mathrm{MeOH}-\mathrm{NiBr}_{2}$ : An Expedient Reagent System for the Synthesis of 2-Amino-2,3Dideoxy Furanosides. Org. Lett. 2006, 8, 1303-1306.

(31) Deck, J. A.; Martin, S. F. Enantioselective Synthesis of (+)-Isolysergol via Ring-Closing Metathesis. Org. Lett. 2010, 12, 2610-2613.

(32) Grehn, L.; Ragnarsson, U. Reagent for Synthesis of Secondary Amines by Two Consecutive N-Alkylations and Its Application to Orthogonally Protected Spermidine. J. Org. Chem. 2002, 67, 65576559.

(33) Nyasse, B.; Grehn, L.; Maia, H. L. S.; Monteiro, L. S.; Ragnarsson, U. 2-Naphthalenesulfonyl as a Tosyl Substitute for Protection of Amino Functions. Cyclic Voltammetry Studies on Model Sulfonamides and their Preparative Cleavage by Reduction. J. Org. Chem. 1999, 64, 7135-7139.

(34) Carraro, M.; Pisano, L.; Azzena, U. Silica Gel Stabilized Na and $\mathrm{Na} / \mathrm{K}$ Alloys: Highly Effective, Versatile and Environmentally Friendly Reducing Agents. Synthesis 2017, 49, 1931-1937.

(35) Nandi, P.; Redko, M. Y.; Petersen, K.; Dye, J. L.; Lefenfeld, M.; Vogt, P. F.; Jackson, J. E. Alkali Metals in Silica Gel (M-SG): A New Reagent for Desulfonation of Amines. Org. Lett. 2008, 10, 5441-5444.

(36) Alonso, E.; Ramón, D. J.; Yus, M. Reductive Deprotection of Allyl, Benzyl and Sulfonyl Substituted Alcohols, Amines and Amides Using a Naphthalene-Catalysed Lithiation. Tetrahedron 1997, 53, $14355-14368$

(37) Ji, S.; Gortler, L. B.; Waring, A.; Battisti, A. J.; Bank, S.; Closson, W. D.; Wriede, P. A. Cleavage of Sulfonamides with Sodium Naphthalene. J. Am. Chem. Soc. 1967, 89, 5311-5312.

(38) Birkinshaw, T. N.; Holmes, A. B. Synthesis of ( \pm )-Isoprosopinines A and B. Tetrahedron Lett. 1987, 28, 813-816.

(39) Roemmele, R. C.; Rapoport, H. Removal of N-Arylsulfonyl Groups from Hydroxy- $\alpha$-Amino Acids. J. Org. Chem. 1988, 53, $2367-2371$.

(40) Shohji, N.; Kawaji, T.; Okamoto, S. Ti(O-i-Pr $)_{4} / \mathrm{Me}_{3} \mathrm{SiCl} / \mathrm{Mg}-$ Mediated Reductive Cleavage of Sulfonamides and Sulfonates to Amines and Alcohols. Org. Lett. 2011, 13, 2626-2629.
(41) Vellemäe, E.; Lebedev, O.; Mäeorg, U. A Mild Method for Cleavage of $\mathrm{N}$-Tos Protected Amines Using Mischmetal and $\mathrm{TiCl}_{4}$. Tetrahedron Lett. 2008, 49, 1373-1375.

(42) Schoenebeck, F.; Murphy, J. A.; Zhou, S.; Uenoyama, Y.; Miclo, Y.; Tuttle, T. Reductive Cleavage of Sulfones and Sulfonamides by a Neutral Organic Super-Electron-Donor (S.E.D.) Reagent. J. Am. Chem. Soc. 2007, 129, 13368-13369.

(43) O'Sullivan, S.; Doni, E.; Tuttle, T.; Murphy, J. A. Metal-Free Reductive Cleavage of C-N and S-N Bonds by Photoactivated Electron Transfer from a Neutral Organic Donor. Angew. Chem., Int. Ed. 2014, 53, 474-478.

(44) Hanson, S. S.; Doni, E.; Traboulsee, K. T.; Coulthard, G.; Murphy, J. A.; Dyker, C. A. Pushing the Limits of Neutral Organic Electron Donors: A Tetra(iminophosphorano)-Substituted Bispyridinylidene. Angew. Chem., Int. Ed. 2015, 54, 11236-11239.

(45) Viaud, P.; Coeffard, V.; Thobie-Gautier, C.; Beaudet, I.; Galland, N.; Quintard, J.-P.; Le Grognec, E. Electrochemical Cleavage of Sulfonamides: An Efficient and Tunable Strategy to Prevent $\beta$-Fragmentation and Epimerization. Org. Lett. 2012, 14, 942-945.

(46) Senboku, H.; Nakahara, K.; Fukuhara, T.; Hara, S. Hg Cathode-Free Electrochemical Detosylation of N,N-Disubstituted $p$ Toluenesulfonamides: Mild, Efficient, and Selective Removal of $\mathrm{N}$ Tosyl Group. Tetrahedron Lett. 2010, 51, 435-438.

(47) Coeffard, V.; Thobie-Gautier, C.; Beaudet, I.; Le Grognec, E.; Quintard, J.-P. Mild Electrochemical Deprotection of N-Phenylsulfonyl $N$-Substituted Amines Derived from (R)-Phenylglycinol. Eur. J. Org. Chem. 2008, 2008, 383-391.

(48) Civitello, E. R.; Rapoport, H. The Regioselective Cleavage of Aryl Tosylates by Electrochemical Reduction. J. Org. Chem. 1992, 57, 834-840.

(49) Hamada, T.; Nishida, A.; Yonemitsu, O. Selective Removal of Electron-Accepting $p$-Toluene- and Naphthalenesulfonyl Protecting Groups for Amino Function via Photoinduced Donor Acceptor Ion Pairs with Electron-Donating Aromatics. J. Am. Chem. Soc. 1986, 108, $140-145$

(50) Liu, Q.; Liu, Z.; Zhou, Y.-L.; Zhang, W.; Yang, L.; Liu, Z.-L.; $\mathrm{Yu}, \mathrm{W}$. Photochemical Desulfonylation of N-Tosyl Amides by 2Phenyl-N,N'Dimethylbenzimidazoline (PDMBI). Synlett 2005, 16, $2510-2512$.

(51) Hong, X.; Mejía-Oneto, J. M.; France, S.; Padwa, A. Photodesulfonylation of Indoles Initiated by Electron Transfer from Triethylamine. Tetrahedron Lett. 2006, 47, 2409-2412.

(52) Xuan, J.; Li, B.; Feng, Z.; Sun, G.; Ma, H.; Yuan, Z.; Chen, J.; Lu, L.; Xiao, W. Desulfonylation of Tosyl Amides through Catalytic Photoredox Cleavage of $\mathrm{N}$-S Bond Under Visible-Light Irradiation. Chem. Asian J. 2013, 8, 1090-1094.

(53) Hasegawa, E.; Nagakura, Y.; Izumiya, N.; Matsumoto, K.; Tanaka, T.; Miura, T.; Ikoma, T.; Iwamoto, H.; Wakamatsu, K. Visible Light and Hydroxynaphthylbenzimidazoline Promoted Transition-Metal-Catalyst-Free Desulfonylation of $\mathrm{N}$-Sulfonylamides and N-Sulfonylamines. J. Org. Chem. 2018, 83, 10813-10825.

(54) Hasegawa, E.; Izumiya, N.; Miura, T.; Ikoma, T.; Iwamoto, H.; Takizawa, S.; Murata, S. Benzimidazolium Naphthoxide Betaine Is a Visible Light Promoted Organic Photoredox Catalyst. J. Org. Chem. 2018, 83, 3921-3927.

(55) Hasegawa, E.; Tanaka, T.; Izumiya, N.; Kiuchi, T.; Ooe, Y.; Iwamoto, H.; Takizawa, S.; Murata, S. Protocol for Visible-LightPromoted Desulfonylation Reactions Utilizing Catalytic Benzimidazolium Aryloxide Betaines and Stoichiometric Hydride Donor Reagents. J. Org. Chem. 2020, 85, 4344-4353.

(56) Hunter, C. J.; Boyd, M. J.; May, G. D.; Fimognari, R. VisibleLight-Mediated $N$-Desulfonylation of $N$-Heterocycles Using a Heteroleptic Copper(I) Complex as a Photocatalyst. J. Org. Chem. 2020, 85, 8732-8739.

(57) Mackenzie, I. A.; Wang, L.; Onuska, N. P. R.; Williams, O. F.; Begam, K.; Moran, A. M.; Dunietz, B. D.; Nicewicz, D. A. Discovery and Characterization of an Acridine Radical Photoreductant. Nature 2020, 580, 76-80. 
(58) Zheng, C.; You, S.-L. Transfer Hydrogenation with Hantzsch Esters and Related Organic Hydride Donors. Chem. Soc. Rev. 2012, 41, 2498-2518.

(59) Romero, N. A.; Nicewicz, D. A. Organic Photoredox Catalysis. Chem. Rev. 2016, 116, 10075-10166.

(60) Chen, J.; Hu, X.; Lu, L.; Xiao, W. Visible Light PhotoredoxControlled Reactions of N-Radicals Ions. Chem. Soc. Rev. 2016, 45, 2044-2056.

(61) Cai, B.-G.; Xuan, J.; Xiao, W.-J. Visible Light-Mediated C P Bond Formation Reactions. Sci. Bull. 2019, 64, 337-350.

(62) Wang, P.-Z.; Chen, J.-R.; Xiao, W.-J. Hantzsch Esters: An Emerging Versatile Class of Reagents in Photoredox Catalyzed Organic Synthesis. Org. Biomol. Chem. 2019, 17, 6936-6951.

(63) Huang, W.; Chen, J.; Hong, D.; Chen, W.; Cheng, X.; Tian, Y.; Li, G. Hydrophosphonodifluoromethylation of Alkenes via ThiylRadical/Photoredox Catalysis. J. Org. Chem. 2018, 83, 578-587.

(64) Wang, C.-M.; Song, D.; Xia, P.-J.; Wang, J.; Xiang, H.-Y.; Yang, H. Visible-Light-Promoted Synthesis of 1,4-Dicarbonyl Compounds via Conjugate Addition of Aroyl Chlorides. Chem. Asian J. 2018, 13, 271-274.

(65) Park, G.; Yi, S. Y.; Jung, J.; Cho, E. J.; You, Y. Mechanism and Applications of the Photoredox Catalytic Coupling of Benzyl Bromides. Chem. - Eur. J. 2016, 22, 17790-17799.

(66) Bogonda, G.; Patil, DiV.; Kim, H. Y.; Oh, K. Visible-LightPromoted Thiyl Radical Generation from Sodium Sulfinates: A Radical-Radical Coupling to Thioesters. Org. Lett. 2019, 21, 37743779.

(67) Qi, L.; Chen, Y. Polarity-Reversed Allylations of Aldehydes, Ketones, and Imines Enabled by Hantzsch Ester in Photoredox Catalysis. Angew. Chem., Int. Ed. 2016, 55, 13312-13315.

(68) Lee, K. N.; Lei, Z.; Ngai, M.-Y. $\beta$-Selective Reductive Coupling of Alkenylpyridines with Aldehydes and Imines via Synergistic Lewis Acid/Photoredox Catalysis. J. Am. Chem. Soc. 2017, 139, 5003-5006.

(69) Zhang, J.; Li, Y.; Xu, R.; Chen, Y. Donor-Acceptor Complex Enables Alkoxyl Radical Generation for Metal-Free $\mathrm{C}\left(\mathrm{sp}^{3}\right)-\mathrm{C}\left(\mathrm{sp}^{3}\right)$ Cleavage and Allylation/Alkenylation. Angew. Chem., Int. Ed. 2017, 56, 12619-12623.

(70) Li, Y.; Zhang, J.; Li, D.; Chen, Y. Metal-Free C( $\left.\mathrm{sp}^{3}\right)-\mathrm{H}$ Allylation via Aryl Carboxyl Radicals Enabled by Donor-Acceptor Complex. Org. Lett. 2018, 20, 3296-3299.

(71) Wu, J.; Grant, P. S.; Li, X.; Noble, A.; Aggarwal, V. K. CatalystFree Deaminative Functionalizations of Primary Amines by Photoinduced Single-Electron Transfer. Angew. Chem., Int. Ed. 2019, 58, $5697-5701$.

(72) Konev, M. O.; Cardinale, L.; Jacobi von Wangelin, A. CatalystFree $N$-Deoxygenation by Photoexcitation of Hantzsch Ester. Org. Lett. 2020, 22, 1316-1320.

(73) Zhu, D.-L.; Wu, Q.; et al. Hantzsch Ester as a Visible-Light Photoredox Catalyst for Transition-Metal-Free Coupling of Arylhalides and Arylsulfinates. Chem. - Eur. J. 2020, 26, 3484-3488.

(74) Chen, W.; Tao, H.; Huang, W.; Wang, G.; Li, S.; et al. Hantzsch Ester as a Photosensitizer for the Visible-Light-Induced Debromination of Vicinal Dibromo Compounds. Chem. - Eur. J. 2016, 22, 9546-9550.

(75) Chang, J. J.; Chan, B.; Ciufolini, M. A. Synthetic Studies toward Spiroleucettadine. Tetrahedron Lett. 2006, 47, 3599-3601.

(76) Alam, M. S.; Koo, S. Deprotection of Durable Benzenesulfonyl Protection for Phenols -Efficient Synthesis of Polyphenols. Synth. Commun. 2018, 48, 247-254.

(77) Cons, B. D.; Bunt, A. J.; Bailey, C. D.; Willis, C. L. Total Synthesis of (-)-Blepharocalyxin D and Analogues. Org. Lett. 2013, 15, 2046-2049.

(78) Masnovi, J.; Koholic, D. J.; Berki, R. J.; Binkley, R. W. Reductive Cleavage of Sulfonates. Deprotection of Carbohydrate Tosylates by Photoinduced Electron Transfer. J. Am. Chem. Soc. 1987, 109, 2851-2853.

(79) Nishida, A.; Hamada, T.; Yonemitsu, O. Hydrolysis of Tosyl Esters Initiated by an Electron Transfer from Photoexcited ElectronRich Aromatic Compounds. J. Org. Chem. 1988, 53, 3386-3387.
(80) Bordwell, F. G. Equilibrium Acidities in Dimethyl Sulfoxide Solution. Acc. Chem. Res. 1988, 21, 456-463.

(81) Olmstead, W. N.; Margolin, Z.; Bordwell, F. G. Acidities of Water and Simple Alcohols in Dimethyl Sulfoxide Solution. J. Org. Chem. 1980, 45, 3295-3299.

(82) Bordwell, F. G.; Drucker, G. E.; Fried, H. E. Acidities of Carbon and Nitrogen Acids: The Aromaticity of the Cyclopentadienyl Anion. J. Org. Chem. 1981, 46, 632-635.

(83) Bordwell, F. G.; Algrim, D. J. Acidities of Anilines in Dimethyl Sulfoxide Solution. J. Am. Chem. Soc. 1988, 110, 2964-2968.

(84) Budén, M. E.; Bardagí, J. I.; Puiatti, M.; Rossi, R. A. Initiation in Photoredox $\mathrm{C}-\mathrm{H}$ Functionalization Reactions. Is Dimsyl Anion a Key Ingredient? J. Org. Chem. 2017, 82, 8325-8333.

(85) Budén, M. E.; Guastavino, J. F.; Rossi, R. A. RoomTemperature Photoinduced Direct C-H-Arylation via Base-Promoted Homolytic Aromatic Substitution. Org. Lett. 2013, 15, 1174-1177.

(86) Bardagí, J. I.; Vaillard, S. E.; Rossi, R. A. Anions from Dihydro Substituted Ethyl Benzoates and Quinoline. New Hydrogen Donors for Tin-Free Radical Chemistry. Tetrahedron Lett. 2006, 47, 31493152.

(87) Vaillard, S. E.; Postigo, A.; Rossi, R. A. Fast Tin-Free Hydrodehalogenation and Reductive Radical Cyclization Reactions: A New Reduction Process. J. Org. Chem. 2004, 69, 2037-2041.

(88) See Supporting Information.

(89) Wei, Y.; Gong, Y.; Zhao, X.; Wang, Y.; Duan, R.; Chen, C.; Song, W.; Zhao, J. Ligand Directed Debromination of Tetrabromodiphenyl Ether Mediated by Nickel under Visible Irradiation. Environ. Sci. Nano 2019, 6, 1585-1593.

(90) Nguyen, J. D.; D’Amato, E. M.; Narayanam, J. M. R.; Stephenson, C. R. J. Engaging Unactivated Alkyl, Alkenyl and Aryl Iodides in Visible-Light-Mediated Free Radical Reactions. Nat. Chem. 2012, 4, 854-859.

(91) Michelet, B.; Deldaele, C.; Kajouj, S.; Moucheron, C.; Evano, G. A General Copper Catalyst for Photoredox Transformations of Organic Halides. Org. Lett. 2017, 19, 3576-3579.

(92) Li, K.; Wan, Q.; Yang, C.; Chang, X.-Y.; Low, K.-H.; Che, C.M. Air-Stable Blue Phosphorescent Tetradentate Platinum(II) Complexes as Strong Photo-Reductant. Angew. Chem. 2018, 130, 14325-14329.

(93) Cahard, E.; Schoenebeck, F.; Garnier, J.; Cutulic, S. P. Y.; Zhou, S.; Murphy, J. A. Electron Transfer to Benzenes by Photoactivated Neutral Organic Electron Donor Molecules. Angew. Chem., Int. Ed. 2012, 51, 3673-3676.

(94) Xu, Z.; Gao, L.; Wang, L.; Gong, M.; Wang, W.; Yuan, R. Visible Light Photoredox Catalyzed Biaryl Synthesis Using Nitrogen Heterocycles as Promoter. ACS Catal. 2015, 5, 45-50.

(95) Hasegawa, E.; Izumiya, N.; Fukuda, T.; Nemoto, K.; et al. Visible Light-Promoted Reductive Transformations of Various Organic Substances by Using Hydroxyaryl-Substituted Benzimidazolines and Bases. Tetrahedron 2016, 72, 7805-7812.

(96) Schmalzbauer, M.; Ghosh, I.; König, B. Utilising Excited State Organic Anions for Photoredox Catalysis: Activation of (Hetero)aryl Chlorides by Visible Light-Absorbing 9- Anthrolate Anions. Faraday Discuss. 2019, 215, 364-378.

(97) Matsubara, R.; Yabuta, T.; Idros, U.; Hayashi, M.; Ema, F.; Kobori, Y.; Sakata, K. UVA- and Visible-Light-Mediated Generation of Carbon Radicals from Organochlorides Using Nonmetal Photocatalyst. J. Org. Chem. 2018, 83, 9381-9390.

(98) Neumeier, M.; Sampedro, D.; Neumeier, M.; Májek, M.; de la Peña O'Shea, V. A.; von Wangelin, A. J.; Pérez-Ruiz, R. Dichromatic Photocatalytic Substitutions of Aryl Halides with a Small Organic Dye. Chem. - Eur. J. 2018, 24, 105-108.

(99) Zhang, L.; Jiao, L. Visible-Light-Induced Organocatalytic Borylation of Aryl Chlorides. J. Am. Chem. Soc. 2019, 141, 91249128.

(100) Discekici, E. H.; Treat, N. J.; Poelma, S. O.; Mattson, K. M.; Hudson, Z. M.; Luo, Y.; Hawker, C. J.; de Alaniz, J. R. A Highly Reducing Metal-Free Photoredox Catalyst: Design and Application in Radical Dehalogenations. Chem. Commun. 2015, 51, 11705-11708. 
(101) Ghosh, I.; Ghosh, T.; Bardagi, J. I.; König, B. Reduction of Aryl Halides by Consecutive Visible Light-Induced Electron Transfer Processes. Science 2014, 346, 725-728.

(102) Gong, H. X.; Cao, Z.; Li, M. H.; Liao, S. H.; Lin, M. J. Photoexcited Perylene Diimide Radical Anions for the Reduction of Aryl Halides: A Bay-Substituent Effect. Org. Chem. Front. 2018, 5, 2296-2302.

(103) Zhu, D. L.; Wu, Q.; Li, H. Y.; Li, H. X.; Lang, J. P. Hantzsch Ester as a Visible-Light Photoredox Catalyst for Transition-MetalFree Coupling of Arylhalides and Arylsulfinates. Chem. - Eur. J. 2020, 26, 3484-3488.

(104) Wang, L.; Neumann, H.; Beller, M. Palladium-Catalyzed Methylation of Nitroarenes with Methanol. Angew. Chem. 2019, 131, $5471-5475$.

(105) Irshad, M.; Abbasi, M. A.; Aziz-Ur-Rehman; Rasool, S.; Siddiqui, S. Z.; Ahmad, I.; Ashraf, M.; Lodhi, M. A.; Jamal, S. B. Oand $\mathrm{N}$-Substituted Derivatives of Planetol as Valuable Bioactive Compounds. Asian J. Chem. 2014, 26, 1151-1160.

(106) Huang, M.; Li, Y.; Li, Y.; Liu, J.; Shu, S.; Liu, Y.; Ke, Z. Room Temperature $\mathrm{N}$-Heterocyclic Carbene Manganese Catalyzed Selective $\mathrm{N}$-Alkylation of Anilines with Alcohols. Chem. Commun. 2019, $55,6213-6216$

(107) Chen, J.; Wu, J.; Tu, T. Sustainable and Selective Monomethylation of Anilines by Methanol with Solid Molecular NHC-Ir Catalysts. ACS Sustainable Chem. Eng. 2017, 5, 1174411751.

(108) Shang, Y.; Jonnada, K.; Yedage, S. L.; Tu, H.; Zhang, X.; Lou, X.; Huang, S.; Su, W. Rhodium(III)-Catalyzed Indole Synthesis at Room Temperature Using the Transient Oxidizing Directing Group Strategy. Chem. Commun. 2019, 55, 9547-9550. 